Title:

\title{
Health-Related Effects and Improving Extractability of Cereal Arabinoxylans
}

\section{Authors:}

Abdulmannan Fadel ${ }^{1} \uparrow$, Ayman M. Mahmoud†*, Jason J. Ashworth ${ }^{5}$, Weili Li ${ }^{6}, \mathrm{Yu} \mathrm{Lam} \mathrm{Ng}^{1}$, Andrew Plunkett ${ }^{1}$

\section{Institutions:}

${ }^{1}$ Department of Food and Nutrition, School of Health Psychology and Social Care, Manchester Metropolitan University, Manchester, United Kingdom.

${ }^{2}$ Physiology Division, Department of Zoology, Faculty of Science, Beni-Suef University, Egypt.

${ }^{3}$ Department of Endocrinology, Diabetes and Nutrition, Charité-University Medicine Berlin, Germany.

${ }^{4}$ Department of Endocrinology, Diabetes and Nutrition at the Center for Cardiovascular Research (CCR), Charité-University Medicine Berlin, Germany.

${ }^{5}$ School of Healthcare Science, Faculty of Science and Engineering, Manchester Metropolitan University, Manchester, United Kingdom.

${ }^{6}$ Institute of Food Science \& Innovation, University of Chester, Chester, United Kingdom. 


\begin{abstract}
:
Arabinoxylans (AXs) are major dietary fibers. They are composed of backbone chains of $\beta-(1-$ 4)-linked xylose residues to which $\alpha$-L-arabinose are linked in the second and/or third carbon positions. Recently, AXs have attracted a great deal of attention because of their biological activities such as their immunomodulatory potential. Extraction of AXs has some difficulties; therefore, various methods have been used to increase the extractability of AXs with varying degrees of success, such as alkaline, enzymatic, mechanical extraction. However, some of these treatments have been reported to be either expensive, such as enzymatic treatments, or produce hazardous wastes and are non-environmentally friendly, such as alkaline treatments. On the other hand, mechanical assisted extraction, especially extrusion cooking, is an innovative pretreatment that has been used to increase the solubility of AXs. The aim of the current review article is to point out the health-related effects and to discuss the current research on the extraction methods of AXs.
\end{abstract}

Keywords: Arabinoxylans; Cereal; Dietary fiber; Immunomodulation; Glycemic control. 


\section{Contents:}

1. Introduction 4

2. Arabinoxylans (AXs) 6

3. Health-Related Effects of AXs

3.1. Effect of AXs on postprandial glucose response 7

3.2. Effect of AXs on lipid and cholesterol metabolism 10

3.3. Antioxidant capacity of AXs 11

$\begin{array}{ll}\text { 3.4. Hepatoprotective effect of AXs } & 13\end{array}$

3.5. Immunological effects of AXs $\quad 13$

3.5.1. Immunomodulatory effects of rice bran AX (MGN-3/Biobran) 14

$\begin{array}{ll}\text { 3.5.2. Immunomodulatory effects of rice bran polysaccharides } & 17\end{array}$

4. Arabinoxylan solubility in some cereals and cereal by-products 18

5. Extraction of AXs 21

5.1. Water extraction 21

5.2. Alkaline extraction $\quad 22$

5.3. Enzymatic extraction 23

5.4. Mechanical extraction 25

5.4.1. Microwave-assisted extraction 25

5.4.2. Extrusion pre-treatment 25

6. Conclusions 28

$\begin{array}{ll}\text { References } & 30\end{array}$ 


\section{Introduction:}

Cereal grains contain variable amounts of non-starch polysaccharide (NSP, namely cell wall material). Cereal grains are composed of hemicelluloses, celluloses, and other materials such as lignins and pectins and collectively are known as dietary fiber $[1,2]$.

A large amount of waste is produced in growing cereals and the maximum benefit is not being obtained from it as it is often fed to animals rather than the valuable components being extracted for human use. This occurs because the material is difficult and expensive to breakdown. Hence, there is a need for improved extraction technologies that both improve the extraction yield and reduce the cost of processing it [3-5].

Arabinoxylans (AXs) are the main NSP constituents of many cereals and they are predominantly found in the outer layers (bran) and starchy endosperm (flour) [6,7]. AXs have been reported in many cereals such as maize, rye, barley, oats, sorghum, wheat and rice $[8,9]$. They constitute about $1.37-2.06 \%$ of the wheat endosperm and the water-extractable portion of this is between 0.54 and $0.8 \%$ [10-12]. In rice, they constitute about $4.84-8.5 \%$ of the bran, and the water-extractable portion of this is between $0.2-0.77 \%[13,14]$. Whilst only small portions of the AXs are soluble, it is possible to apply chemical, enzymatic or physical treatments to increasing the extraction yield [15].

AXs are polysaccharides composed of backbone chains of $\beta$-(1-4)-linked d-xylopyranosyl residues to which $\alpha$-L-arabinofuranose units are linked as side chains in the second and/or third carbon positions, so they are often named pentosans [6, 16-19]. The degree of branching is an important factor in determining the physiochemical properties of AXs [20, 21]. A large proportion of AX cannot be solubilized in water due to the formation of di-ferulic acid bridges and covalent ester bonding between carboxyl groups on individual AX chains [6, 22]. In order to solubilize and extract AXs, pre-treatments might be applied e.g. alkaline hydrolysis or 
enzymatic digestion. Each of these pre-treatments have different effects on the solubility and molecular weight of AXs [23-25].

Alkaline treatment is an efficient way for extracting AXs from cell wall materials. However, it changes the functional properties of the AXs by breaking down (hydrolyzing) some functional groups of the AXs, such as ferulic acid, and hence tends to give high molecular weight AXs fractions $(100-200 \mathrm{kDa})[6,24,26]$.

On the other hand, enzymatic treatments increase AXs solubility by attacking the AXs backbone in a different manner, producing lower molecular weight fractions to those produced by alkaline hydrolysis. The enzymatic treatment produces lower molecular weight fractions of AXs with a lower extraction yield $[6,25,27]$. However, this is not as efficient as alkaline hydrolysis and gives rise to different functionality.

Physical pre-treatments have been applied to increase the solubility of dietary fibers such as extrusion $[23,28]$. Extrusion is a process where the materials can be exposed to a combination of temperature, pressure and shear forces, which might lead to a variety of chemical reactions and molecular transformations [29]. Recently, extrusion has been used to increase the solubility of water-extractable AXs (WEAX) in corn fiber [30, 31].

Studies have suggested that low molecular weight AXs extracted from different cereals may have desirable biological effects $[18,32]$. Low molecular weight corn husk and rice bran AXs showed an increase in the activity of natural killer (NK) cells and an increase in cytokine production in vitro $[33,34]$. Other studies found that AXs extracted from enzymatically modified rice bran (Biobran) with low molecular weight can stimulate both the adaptive and innate immune system by enhancing dendritic cell maturation, macrophage phagocytosis, and NK cell activity [35]. On the other hand, large molecular weight AXs extracted from banana peel stimulated macrophage activation $[33,36]$. 
There is inconsistency in the literature, which may be related to the source and the method of AXs extraction. The aim of this review is to provide an overview of the different biological effects and extraction methods of AXs from different cereals.

\section{Arabinoxylans (AXs):}

AXs are NSPs composed of backbone chains of $\beta$-(1-4)-linked d-xylopyranosyl residues to which $\alpha$-L-arabinofuranose units are linked as side chains in the second and/or third carbonpositions $[6,16,17,37]$ (Figure 1). The NSPs are indigestible by human gut enzymes and are therefore referred to as dietary fiber. NSPs makes up $75 \%$ of the cell wall and is composed of glucomannan, (1-3) (1-4) $\beta$ glucan, cellulose and AXs (pentosans) [2, 38]. Pentosans or AXs are the major hemicellulosic polysaccharides in cereals and they make up more than $80 \%$ of the NSP in wheat and $10 \%$ of rice bran [38-40].

AXs' structural characteristics are determined by the substitution of the xylopyranose linked xylan backbone. L-Arabinofuranose is the main substituent sugar and it can substitute for xylopyranose residues at O-2 and/or O-3 via $\alpha-1,2$ and $\alpha-1,3$ glycosidic linkages. This leads to three different forms namely, un-substituted xylopyranose, mono-substituted xylopyranose at O-2 or O-3 and di-substituted xylopyranose at O-2 and O-3 $[8,37,41,42]$. On the other hand, arabinofuranose substitutions can form short oligosaccharide side chains and comprise two or more arabinofuranose residues [41] (Figure 2). Brokaert et al. [42] have reported that D-glucose, D-galactose, glucuronic acids and acetyl groups are substituted at O-2 and/or O-3 of the xylan backbone. This structural diversity of AXs can vary between cereals due to the complexity of tissue components within cereal grains [37, 43, 44]. Ordaz-Ortiz and Sulnier [45] have reported that AXs content is different between wheat endosperm, bran and husks with various arabinose-to-xylose ratios, and that the yield will depend on the method of extraction. 
There are many techniques available for AXs extraction and different extraction methods will give different yields and range of degrees of branching, molecular weight distribution and tertiary conformation [46], i.e. hot water extraction [21, 47-49] and ultrasound-assisted enzymatic extraction [50].

AXs can be classified, according to their solubility in water, as either water-unextractable AXs (WUAX) or water-extractable AXs (WEAX) [51]. The structure of WUAX is somewhat different from that of WEAX; WUAX will not solubilize in water, however, it will be solubilized in alkaline solutions [52].

\section{Health-Related Effects of AXs:}

\subsection{Effect of AXs on postprandial glucose response:}

Diabetes mellitus is a serious, chronic disease that occurs either when the pancreas does not produce enough insulin, or when the body cannot effectively use the insulin it produces [53]. Type 2 diabetes mellitus (T2DM) is characterized by chronic hyperglycemia that results from defective or deficient insulin [54]. T2DM accounts for the vast majority (more than 90\%) of all diabetic patients and its complications constitute a major public health problem [55]. The incidence of T2DM has increased dramatically and the number of patients with diabetes is expected to increase to 642 million by 2040 [56]. Management of postprandial blood glucose is critical in prevention and treatment of T2DM. Results of the human intervention studies have demonstrated that consumption of an AXs-rich diet reduced postprandial blood glucose levels in healthy subjects and diabetic patients. In normoglycemic subjects, Lu et al. [57] reported a significant improvement in the postprandial glucose and insulin responses following consumption of breakfast meals rich in $\mathrm{AX}$ extracted from the byproduct of wheat flour processing. On the other hand, Möhlig et al. [58] demonstrated non-significant differences in

glucose and insulin responses in healthy subjects following consumption of bread rolls 
supplemented with AX. The authors showed increased levels of ghrelin and assumed that the effect of AXs in healthy subjects is unlikely to be mediated by insulin. Recent studies have demonstrated different effects of AXs on postprandial glucose and insulin responses. White bread enriched with AX flour obtained by enzymatic hydrolysis of the bran extracted from the milling process significantly reduced the 30 -min peak postprandial glucose levels in healthy normoglycemic volunteers [59]. In healthy young adults, wheat bran extract rich in AXs significantly improved glucose tolerance and insulin sensitivity in an overnight perspective $[60]$.

Subjects with impaired glucose tolerance (IGT) received $15 \mathrm{~g} \mathrm{AXs} \mathrm{supplement} \mathrm{for} 6$ weeks showed lower postprandial responses in blood glucose, triglycerides and insulin when compared with a placebo group [61]. In this study, total plasma ghrelin was reduced while plasma acylated ghrelin wasn't affected in IGT subjects after AXs consumption [61]. In another study by Garcia et al. [62], the consumption of $15 \mathrm{~g}$ AXs for 6 weeks improved fasting serum glucose, triglycerides and apolipoprotein A-1 levels in subjects with IGT. However, AXs didn't affect insulin, leptin, adiponectin, resistin, apolipoprotein B and unesterified fatty acids in this group of subjects with IGT. Therefore, the beneficial effect of AXs wasn't accompanied by significant changes in fasting levels of adipokines. Long term consumption of water-soluble corn bran hemicellulose decreased fasting blood glucose levels in healthy non-obese subjects and in obese and non-obese patients with IGT. In obese patients with IGT, hemoglobin A1c was decreased significantly during corn bran hemicellulose supplementation. In addition, oral glucose tolerance test (OGTT) and insulin release were improved in patients with IGT as a result of corn bran hemicellulose supplementation [63].

Changes in postprandial glucose kinetics and the glucose-dependent insulinotropic polypeptide (GIP) after the ingestion of fiber-rich products with slowly and rapidly digestible starch have 
been studied by Cho et al. [64]. The consumption of slowly digestible starch compared with the rapidly digestible one resulted in lower postprandial insulin and GIP and a slower rate of appearance of exogenous glucose but a similar glycemic response. The similar glycemic response of both slowly and rapidly digestible starchy foods has been attributed to a slower glucose clearance rate [65].

The beneficial effects of AXs have also been studied in metabolic syndrome and diabetic patients. The metabolic syndrome together with T2DM and cardiovascular diseases (CVD) are the challenging life-style diseases facing modern society. Energy-rich low fiber food is known to impair glucose and lipid metabolism and easy access to this food is linked to metabolic disease, T2DM and CVD [66]. On the other hand, consumption of food rich in cereal fibers has been associated with a lower risk of developing T2DM [67, 68] and CVD [69]. Recently, Schioldan et al. [70] assessed the impact of a healthy carbohydrate diet rich in AXs and resistant starch on postprandial lipaemia and features of the metabolic syndrome. Consumption of the diet for 4 weeks improved fasting total and low-density lipoprotein (LDL)-cholesterol in subjects with metabolic syndrome on statins with no diet related impact on features of the metabolic syndrome [70]. In addition, the intake of AXs-rich diet was associated with a wide range of benefits for diabetic patients. T2DM patients supplemented with AXs-rich diet showed significantly lowered fasting and $2 \mathrm{~h}$ plasma glucose, $2 \mathrm{~h}$ insulin and serum fructosamine [71]. Despite the observed improvement in glycemic control, body weight, fat mass, blood lipids and blood pressure remained unchanged [71]. Studies on experimental animals have also revealed similar findings. Zucker diabetic fatty (ZDF) rats received AXs-rich diet showed a significant decrease in blood glucose response after an OGTT [72].

The mechanisms underlying the beneficial effect of AXs on glycemic control are not fully understood. Studies referred to the inhibitory effect of AXs on $\alpha$-glucosidase represent an attempt to explain its antihyperglycemic properties. In this context, Malunga et al. [73] reported 
the efficacy of feruloylated AX to inhibit the activity of mammalian intestinal $\alpha$-glucosidase, sucrase and maltase as well as glucose transporters. The authors assumed that the fatty acid moiety of feruloyl AX was the active site for this inhibitory activity. In addition, dietary fibers have been proposed to delay nutrient absorption through increasing the lumen viscosity [74]. However, Dhital et al. [75] suggested that the viscosity e $\square$ ect may be o $\square$ set by strong intestinal peristalsis. Therefore, further work is required to understand the mechanisms underlying the effect of AXs on glucose and insulin responses in normoglycemia, obesity, metabolic syndrome and diabetes.

\subsection{Effect of AXs on lipid and cholesterol metabolism:}

The effect of AXs on blood lipids and cholesterol metabolism has been reported in several studies. Supplementation of AXs has shown a lipid-lowering effect in both human and experimental animals. In individuals with metabolic syndrome who received whole-grain wheat and rye for 3 months, Giacco et al. [76] reported a lower $3 \mathrm{~h}$ postprandial triglyceride response despite unchanged fasting triglyceride levels. In another study by Garcia et al. [61], subjects with IGT received $15 \mathrm{~g} /$ day of concentrated wheat AXs for 6 weeks showed decreased 4h postprandial triglyceride response. Recently, Chen et al. [77] reported increased lipid catabolism in high fat diet-induced rats supplemented with AXs.

Wheat AXs have been suggested to reduce blood triglycerides through slowing down their digestion and the absorption of free fatty acids (FFA) [78]. Accordingly, corn bran AXs reduced intestinal cholesterol absorption and cholesterol accumulation in the liver, and enhanced cholesterol excretion in feces [79]. In hypercholesterolemic hamsters, wheat bran AXs decreased total- and LDL-cholesterol levels and increased the excretion of cholesterol and total lipids [80]. Adam et al. [81] have shown decreased plasma cholesterol levels and increased 
cecal short-chain fatty acids (SCFAs) following replacement of the refined wheat flour with whole flour in rats.

In addition to their inhibitory effect on intestinal glucose absorption, AXs modulated the activity of 5-hydroxy-3-methylglutaryl-coenzyme A (HMG-CoA) reductase and cholesterol 7 alpha-hydroxylase (CYP7A1) in the liver [80]. HMG-CoA reductase and CYP7A1 are the ratelimiting enzymes of cholesterol synthesis in the liver [82]. In hamsters fed a hypercholestrolemic diet, supplementation of wheat bran AXs reduced the synthesis of cholesterol and increased its decomposition into bile acids via modulation of HMG-CoA reductase and CYP7A1 [80].

Moreover, supplementation of AXs decreased acetate and increased the production propionate in human and experimental animals [83, 84]. In support of these findings, Chen et al. [77] have recently shown similar findings in rats received high fat diet and AXs. The study of Tong et al. [80] showed increased propionate and total SCFAs concentrations in AXs-supplemented animals. They postulated that the hypocholesterolemic effect of AXs is related to increased colonic SCFAs and fecal lipids output.

\subsection{Antioxidant capacity of AXs:}

Reactive oxygen species (ROS) play a key role in intra- and intercellular signaling [85]. The excessive production of ROS is associated with cell damage and contributes to many pathological conditions and diseases [85]. The role of AXs in preventing chronic health problems associated with excessive production of ROS and oxidative stress has been wellacknowledged. Non-nutrient phytochemicals and dietary fibers of cereal bran showed a protective effect against oxidative stress [86-88]. Wheat bran feruloyl oligosaccharides showed an antioxidant capacity against oxidative stress and enhanced antioxidant defenses in diabetic rats [89]. Normal rat erythrocytes treated with feruloyl oligosaccharides were protected against 
hemolysis induced by free radicals [90]. Feruloyl arabinose, isolated from maize bran by acid hydrolysis, showed an in vitro antioxidant activity evidenced by different radical scavenging assays [91]. In high fat diet-fed rats treated with AXs, Chen et al. [77] demonstrated decreased lipid peroxidation and increased superoxide dismutase and glutathione peroxidase in the liver.

Previous studies showed that the presence of hydroxycinnamic acids provides antioxidant capacity to AXs. The overall radical scavenging activity of xylooligosaccharides and xylans of the wheat bran has also been attributed to the contained hydroxycinnamic acids $[92,93]$. The studies of Malunga and Beta [94] and Bagdi et al. [95] reported that the radical scavenging activity of AXs is associated with the presence of ferulic acid, and Snelders et al. [96] determined the role of ferulic acid content and appearance in the antioxidant capacity of AXs. Interestingly, feruloyl oligosaccharides showed a stronger in vitro antioxidant activity than that of a free ferulic acid [97]. The antioxidant capacity of AXs has also been linked to the molecular characteristics in addition to the phenolic compounds [98-101]. The number of sugar molecules linked by ferulic acid contributes to the antioxidant activity. Therefore, the antioxidant activity of AXs could be increased with a higher number of sugar molecules [100, 101].

The antioxidant effect of AXs could also be explained, at least in part, through their ability to activate the nuclear factor erythroid 2-related factor 2 (Nrf2). The redox-sensitive transcription factor Nrf2 plays a major role in protecting the cells against ROS through its ability to bind to the antioxidant response element (ARE) and activate the expression of antioxidant genes [85]. Zhang et al. [102] determined the antioxidant effect of wheat bran feruloyl oligosaccharides in rats. When supplemented at doses of $0.25,0.5$, and $0.75 \mathrm{mmol} / \mathrm{kg} / \mathrm{day}$ for 15 days, feruloyl oligosaccharides increased the activity of heme oxygenase-1, superoxide dismutase, catalase and glutathione peroxidase in the heart, liver, and kidney of rats. These effects were mediated through the activation of Nrf2 following treatment with feruloyl oligosaccharides. Activation of Nrf2 has been reported to enhance the antioxidant defenses and protect against oxidative 
stress in drug-induced liver injury [103-105], endothelial dysfunction [106, 107], hyperammonemia [108] and hepatocarcinogenesis [109, 110]. Therefore, further studies are required to trace out the mechanisms underlying AXs-mediated activation of Nrf2.

\subsection{Hepatoprotective effect of AXs:}

Few studies have demonstrated the hepatoprotective effects of AXs. In an animal model of hepatitis induced by D-Galactosamine (GalN), Zheng et al. [111] showed the suppressive effect of a modified AX from rice bran (MGN-3) and its active fraction on IL-18 expression. In this study, GalN-induced hepatitis model has been selected because of its similar morphological and pathophysiological characteristics to those of human hepatitis B [112]. The same group reported that the hepatoprotective efficacy of MGN-3 is mediated via inhibition of nuclear factor- $\kappa \mathrm{B}(\mathrm{NF}-\kappa \mathrm{B})$ and JNK/MAPK expression in the liver of GalN-induced rats [113]. In 2016, Salama et al. [114] reported the suppressive effect of rice bran AX (Biobran) on the viremia level in patients with chronic hepatitis $\mathrm{C}$ virus (HCV) infection. Sixteen patients with chronic HCV received $1 \mathrm{~g}$ /day Biobran for 3 months and viremia, interferon- $\gamma($ IFN- $\gamma)$ and liver enzymes were assessed before and after treatment. Biobran significantly reduced viremia and increased the level of serum IFN- $\gamma$. More interestingly, patients received Biobran showed no side effects when compared with patients treated with PEGylated interferon plus ribavirin who experienced anemia, thrombocytopenia, fever and easy fatigue [114]. A recent study by Chen et al. [77] showed the protective effect of AXs against liver injury in high fat diet-fed rats. The protective effect of AXs against liver injury induced by drugs, environmental chemicals and other factors remains a relatively untapped field of research.

\subsection{Immunological effects of AXs:}

The effects of AXs on innate and acquired immune response have been well-documented. The immunomodulatory potential of AXs is controlled by several factors, including the source, 
molecular weight and degree of arabinose and xylose substitution. Many reports suggested that both low and high molecular weight AXs possess potentials to enhance the immune response $[6,26,32,115]$. In this context, Cao et al. [26] investigated the effect of high molecular weight AX from wheat bran on immunological responses in S 180 tumour-bearing mice. High molecular weight AX inhibited interleukin-2 (IL-2) production and tumour growth, and increased blood leukocytes. Low molecular weight wheat bran AX as well showed potent immunological activities. Zhou et al. [6] investigated the immunoregulatory effects of low molecular weight AXs extracted by alkaline- and enzyme-based methods from wheat bran. In female BALB/c mice, both AXs had potent stimulating effects on immune response with the one extracted by the enzyme-based method showed a stronger effect on macrophage $(\mathrm{M} \varphi)$ phagocytosis and delayed hypersensitivity reaction [6]. Modified AXs from enzymatically modified rice bran (knows commercially as Biobran) with low molecular weight have the potential to stimulate the immune system through improving the maturation of dendritic cells and enhancing the phagocytosis, as well as increasing NK cells activity [31, 32, 115, 116]. Therefore, it can be postulated that the source and method of extraction affect the molecular weight distribution and degree of substitution which will ultimately affect the immunological activities of AXs. Some of the structural properties of AXs in relation to the extraction method and immunomodulatory activity in rice bran and wheat bran are summarized in Table 1.

\subsubsection{Immunomodulatory effects of rice bran AX (MGN-3/Biobran):}

MGN-3/Biobran is composed of a xylose backbone attached to arabinose monomers with a moelcular weight range of 30-50 $\mathrm{kDa}$ [117]. Several in vitro and in vivo studies as well as human trials reported the capability of MGN-3 to enhacne the innate and adaptive immune cells such as macrophages, dendritic cells, NK cells, and B and T lymphocytes [118-121]. Yet, the mechanism of AXs action is not fully understood. However, it has been suggested that 
reducing the length of $\mathrm{AX}$ chain which will reduce its molecular weight, thus AXs might be took up by M cells (microfold cells) of Peyer's patches in the small intestine. AXs might be transported to the immune cells and then circulated in the blood stream [122]. Furthermore, Ghoneum and Jewett [123] suggested that AXs can be transformed from the small intestines into the bloodstream through the lymph nodes.

Several in vitro studies investigated the immunological effects of MGN-3. It has been reported that MGN-3 facilitates the maturation of monocytes and transfer it to dendritic cells in the presence of pro-inflammatory inducers lipopolysaccharide (LPS), IFN- $\gamma$, IL- $1 \beta$, tumor necrosis factor alpha (TNF- $\alpha$ ) and IL-6 [124]. MGN-3 showed an increase in phagocytosis by U937 macrophages. It was also reported that MGN-3 can increase the TNF- $\alpha$ and IL-6 in treated macrophages from U937 and RAW264.7 (murine macrophage cell line) [121, 125]. MGN-3, in a dose-dependent manner, increased DEC-20S expression and the production of Type III IFN and IL-29 in dendritic cells, suggesting that MGN-3 has the potential to activate dendritic cells. Therefore, MGN-3 might be used for augmenting an efficient immune response against infectious diseases and cancer [121].

The effect of MGN-3 on the immune response has been studied in animals. MGN-3 stimulated NK cell cytotoxic activity against neuroblastoma in vivo [117] and enhanced the apoptosis of tumor cells in Ehrlich ascites carcinoma (EAC)-bearing mice [120]. It was found that inhibition of tumor growth after MGN-3 treatment was associated with an increase in apoptosis and DNA damage of tumor cells, as well as a decrease in cancer cell proliferation. Their findings suggest that supplementation of MGN-3 can enhance tumor cell demise [118]. Badr El-Din et al. [120] investigated the effect of intra-tumoral and intra-peritoneal supplementation of MGN-3 on EAC-bearing mice, reporting that a concentration of $40 \mathrm{mg} / \mathrm{kg}$ body weight of MGN-3 can delay tumor growth. The inhibitory effect of MGN-3 treatment on tumor growth had positive 
effects from day 14 post-injection, with tumor weight and volume reducing by $45 \%$ and $63 \%$ respectively in mice at day 35 . Moreover, MGN-3 showed antitumor effects and an increase in IFN- $\gamma$ production by $154 \%$, apoptotic activity of $76 \%$, TNF- $\alpha$ secretion of $11 \%$ and NK cell activity of $100 \%$. These results suggested that the antitumor effect of MGN-3 is due to its ability to induce IFN- $\gamma$ and TNF- $\alpha$.

Although several in vitro and in vivo studies have been conducted to investigate the biological activities of MGN-3, few studies have examined its immunological effects in humans. In a study conducted by Ghoneum and Brown [126], 32 cancer patients ingested 3g of MGN-3 every day for a month. It was found that the ingestion of MGN-3 significantly improved NK cell cytotoxicity by a 10 -fold. Moreover, MGN-3 enhanced B cell and T cell function in all cancer patients throughout measuring proliferation activity of $\mathrm{B}$ and $\mathrm{T}$ cells against several mitogens. Furthermore, no hypo-responsiveness in patients was observed post treatment, suggesting that MGN-3 is nontoxic, and its use could be encouraged in conjunction with chemotherapy in order to dampen the effect of immunosuppression. In a study conducted in 32 multiple myeloma patients, MGN-3 was administered on a daily basis for 3 months. It was demonstrated that MGN-3-treated patients had higher NK activity compared to the placebo group. Moreover, the level of myeloid dendritic cells had significantly increased, suggesting MGN-3 may participate in activation of the innate immunity of multiple myeloma patients [116]. Recently, the effect of MGN-3 in patients with chronic HCV infection has been studied [114]. MGN-3 significantly reduced viremia and increased the level of serum IFN- $\gamma$ and showed no side effects [114]. The immunomodulatory potential of MGN-3 is well documented in vitro, in vivo and humans. However, MGN-3 is a modified form of AXs from rice bran, and there is limited research on the non-modified rice bran AXs and other polysaccharides. 


\subsubsection{Immunomodulatory effects of rice bran polysaccharides:}

There is a limited research on the polysaccharides extracted from rice bran without modification, including AXs. In 2008, Wang et al. [127] studied the effect of a rice bran heteropolysaccharide (RBPS2a) extracted with hot water on anti-complementary activity. The study indicated that RBPS2a has the ability to induce red blood cell lysis and complement consumption through residual complement activity. In another study, different fraction of $\mathrm{AX}$ was extracted from rice bran using carbohydrate hydrolysing enzymes for a longer period [128]. The extracted AX had a low molecular weight and structure similar to MGN-3. Mast cells treated with $0.3 \mathrm{mg} / \mathrm{ml}$ rice bran $\mathrm{AX}$ showed a remarkable depletion in $\beta$-hexosamindase secretion post-antigen stimulation. In addition, IL-4 and TNF- $\alpha$ secretion were inhibited after treating the mast cells with the AX, proposing that AXs extracted from rice bran have the ability to suppress cytokine secretion and degranulation of mast cells [128]. In a recent study, feruloylated AXs from rice bran induced IL-6, IL-1 $\beta$, prostaglandin E2 (PGE2), nitric oxide (NO) and TNF- $\alpha$ in RAW264.7 macrophages, suggesting that feruloylated AXs may be able to enhance innate immunity and protect against chronic inflammatory diseases [129]. More recently, Wang et al. [130] investigated the effect of rice bran polysaccharides on NO and TNF$\alpha$ production in RAW264.7 macrophages. Their results suggest that the antitumor activity of rice bran polysaccharides is mediated through macrophage activation which in turn induces the secretion of NO and TNF- $\alpha$ in a dose-dependent manner. 
Table 1. Structural properties of and immunomodulatory activity of AXs.

\begin{tabular}{|c|c|c|c|c|c|c|c|c|c|}
\hline Origin & $\begin{array}{l}\text { Extraction } \\
\text { method }\end{array}$ & $\begin{array}{l}\text { Immunomodulatory } \\
\text { activity }\end{array}$ & $\begin{array}{c}\text { Mw } \\
(\mathrm{kDa})\end{array}$ & Glu\% & $\begin{array}{c}\text { Gal } \\
\%\end{array}$ & $\begin{array}{c}\text { Xyl } \\
\%\end{array}$ & $\begin{array}{c}\text { Ara } \\
\%\end{array}$ & Ara/Xyl & References \\
\hline Wheat bran & Alkaline & $\begin{array}{l}\text { Tumor inhibition, } \\
\text { M } \varphi \text { activation }\end{array}$ & 352 & 7.7 & NA & 50.2 & 41.8 & 0.83 & [6] \\
\hline Wheat bran & Enzyme & $\mathrm{M} \varphi$ activation & 32.5 & 2.8 & NA & 62.4 & 34.8 & 0.55 & [6] \\
\hline Wheat & Alkaline & $\begin{array}{l}\text { Dendritic cell } \\
\text { activation, TNF- } \alpha \\
\text { and IL-1Ra }\end{array}$ & $\begin{array}{l}100- \\
1000\end{array}$ & - & - & 35 & 67 & 0.52 & {$[131]$} \\
\hline Rice bran & Enzyme & $\begin{array}{l}\mathrm{M} \varphi \text {, dendritic cells } \\
\text { and } \mathrm{NK} \text { activation }\end{array}$ & $30-50$ & 6 & $5-7$ & $\begin{array}{l}48- \\
54\end{array}$ & $\begin{array}{l}22- \\
26\end{array}$ & 0.5 & {$[44]$} \\
\hline $\begin{array}{l}\text { Finger millet } \\
\text { bran }\end{array}$ & $\begin{array}{c}\mathrm{KOH} \text { and } \\
\mathrm{BaOH}\end{array}$ & $\begin{array}{l}\text { Lymphocyte } \\
\text { proliferation, nitric } \\
\text { oxide }(\mathrm{NO}) \\
\text { production and } \mathrm{M} \varphi \\
\text { activation }\end{array}$ & $40-1028$ & - & - & - & - & 0.83 & {$[132,133]$} \\
\hline
\end{tabular}

Glu, glucose; Gal, galactose; Xyl, xylose; Ara, Arabinose;

\section{AXs solubility in some cereals and cereal by-products:}

As mentioned previously, AXs in cereals and cereals by-products can be classified into WEAX and WUAX $[51,134]$. It has been reported that AXs in rye are part of the cell wall material and they are bound covalently and non-covalently to other cell wall materials such as proteins, cellulose or lignin $[135,136]$. In contrast, AXs in wheat are loosely bound to the surface of the cell wall $[38,137]$. Sasaki [138] suggested that the difference in water extractability of AXs in cereals is due to the degree of cross-linking with other cell wall materials. These cross-links can be covalent ester bonds between the carboxylic acid group of uronic acids and AXs hydroxyl groups, or diferulic acid bridges between adjacent AXs chains $[15,37,139]$. It was reported that wheat endosperm contains between $31-111 \mathrm{mg} / 100 \mathrm{~g}$ ferulic acid $[140,141]$, whereas, rice bran contains $303 \mathrm{mg} / 100 \mathrm{~g}$ [142]. It also has been reported that ferulic acid side chains are esterified to some arabinose residues [143]. These cross-links make the extraction 
of AXs difficult and there is a need to use other treatments such as enzymes, alkali solutions or mechanical treatments to effectively remove the AXs from what is a very stable network of covalent and non-covalent cross-links [144, 145]. Moreover, the low solubility of AXs might be due to the close packing of the cell content, which is proposed to be due to steric hindrance [146].

Previous studies have shown that the percentage of WEAX is generally far lower than the WUAX in cereals or cereal by-products (Table 2). Therefore, increasing and improving WUAX solubility has been very important for those who are interested in converting WUAX to WEAX. It has been reported that treating WUAX with alkali resulted in releasing WUAX from cell wall material due to the breaking down of bridges between the AXs and the covalent bonds and hydrogen atoms of the cell wall material [147]. In a later study carried out by Courtin and Delcour [144], the possibility of increasing the extractability of AXs from wheat using enzymes was investigated. WUAX treated with endoxylanases resulted in an increase in the solubility of AXs due to the degradation of the xylan backbone. Additionally, this resulted in a reduction in the molecular weight of the extracted AXs fraction [115]. There is a limit to the increase in solubility from treating with endoxylanase due to the branched sections, which are not affected by the endoxylanase treatment. On the other hand, several reports show that AXs' solubility depends on the AXs' degree of branching [148, 149]. AXs with high arabinose substitutions have a higher solubility in water and vice versa. 
Table 2. WEAX and WUAX in some cereals (dry weight basis).

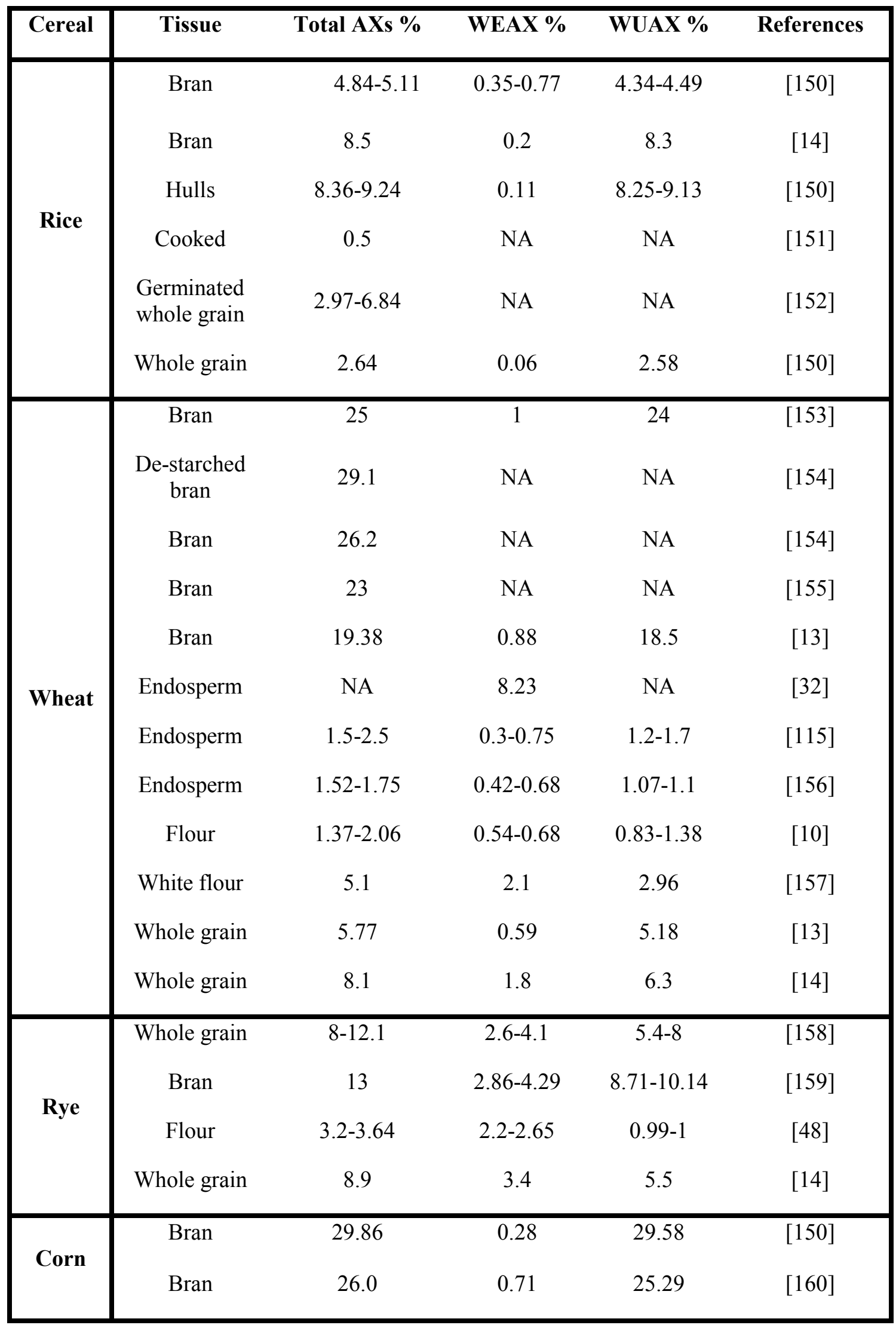




\section{Extraction of AXs:}

Most of the AXs in the intact cell walls of cereals are cross-linked with other cell wall materials to form a structural complex, which is not soluble in water. Therefore, there is a need to increase the extraction yields through improving the solubility of the WUAXs fraction [150]. Several methods have been developed, investigated and reported for the extraction and purification of AXs [144]. These include water extraction $[22,115,153]$ enzyme hydrolysis $[115,161]$, acid and alkaline extraction $[6,147,148,153]$ and mechanically assisted treatment in the form of extrusion $[30,158]$.

\subsection{Water extraction:}

Extraction using water is one of the most common methods used to isolate AXs from different cereals, followed by precipitation with $65 \%$ ethanol $[162,163]$. Using water alone to extract AXs has several advantages such as it is environmentally friendly, cheap, available and edible. It has been reported that the extraction yield of WEAX from two barley cultivars varies depending on barley sub-fraction and varieties [164]. In 2003, Cyran et al. [48] reported that the extraction yields of WEAX in rye flour were $1.1-1.4 \%$ at $4^{\circ} \mathrm{C}, 0.17-0.33 \%$ at $40^{\circ} \mathrm{C}$ and $0.41-0.51 \%$ at $100^{\circ} \mathrm{C}$. It has been reported that the yield of AXs achieved by the enzymatic and chemical methods is higher than that achieved by the water method. It is suggested that combining water with gentle conditions (i.e. a temperature below $100^{\circ} \mathrm{C}$ ) is not sufficient to break the cross-linkages between AXs and the cell wall matrix [165]. To counter this, water extraction combined with hydrothermal techniques have been developed, using high pressure $(5-40 \mathrm{MPa})$ and high temperature at $\left(200-600^{\circ} \mathrm{C}\right)$, to increase the extraction yield of hemicelluloses to $65-90 \%$ [166-169]. However, it has been indicated that although these techniques are environmentally friendly, they degrade the hemicellulose structure, which may damage the structure of the AX, which in turn may affect its functionality [168]. As a 
significant amount of AXs remain after water extraction, some researchers have dismissed water extraction methods in preference to enzyme and alkali treatments [153].

\subsection{Alkaline extraction:}

This method of extraction involves disrupting covalent and hydrogen bonds in the matrix of polysaccharides to liberate various polysaccharides from the cell wall [24, 153]. Hydrogen bonds between hemicellulose and cellulose can be disrupted by hydroxyl ions, and hydrolysis of the ester linkages, which in turn solubilizes part of the hemicellulose material [47]. On the other hand, under alkaline conditions, uronic acids change to their negatively charged form, causing repulsion between different molecules, which results in an increase in the extractability the AXs present [153].

There are several techniques developed to extract AXs using alkaline solutions. The first such solution used to release WUAX from cereals was barium hydroxide, which was introduced by Gruppen et al. [147]. Barium ions form insoluble complexes with $\beta$ glucans, resulting in the release of $80 \%$ of the WUAX from wheat flour. Additionally, Bergmans et al. [170] reported that $50 \%$ of WUAX was extracted from wheat bran using this technique.

On the other hand, dilute alkaline solutions such as hydrogen peroxide $\left(\mathrm{H}_{2} \mathrm{O}_{2}\right)$ have been used to extract WUAX, resulting in yields of around $69 \%$ of the total AXs content, from wheat bran $[148,171]$. Although alkaline extraction yield is higher than the water extraction, alkaline extraction has been reported to affect the molecular structure of AXs due to the disruption of cross-linkages, resulting in different molecular structures in WUAX than that would occur naturally, which in turn results in different functional characteristics $[172,173]$. The extraction yields of AXs and hemicelluloses using different alkaline solutions from rice and wheat brans are shown in Table 3. 
Table 3. AXs and hemicelluloses extraction yield using alkaline solutions.

\begin{tabular}{|c|cccc|}
\hline Sources & Extraction & $\begin{array}{c}\text { Yield\% of } \\
\mathbf{A X s}_{(\mathbf{a})} / \text { hemicellulose }_{(\mathbf{b})}\end{array}$ & Ara/Xyl & References \\
\hline Wheat bran & $0.5 \% \mathrm{H}_{2} \mathrm{O}_{2}(0.15 \mathrm{M} \mathrm{NaOH} \mathrm{v} / \mathrm{v})$ & 18.5 & 0.8 & {$[6]$} \\
Wheat bran & $0.44 \mathrm{M} \mathrm{NaOH}(\mathrm{pH} 12.5)$ & 34.30 & 0.54 & {$[174]$} \\
$\begin{array}{c}\text { Wheat bran } \\
\text { Wheat } \\
\text { endosperm }\end{array}$ & $0.5 \mathrm{M} \mathrm{NaOH}$ & 48.1 & 0.64 & {$[175]$} \\
Corn bran & $4.27 \mathrm{M} \mathrm{KOH}$ & $56 \mathrm{a}$ & 0.91 & {$[38]$} \\
Rice straw & $1 \% \mathrm{NaOH} \mathrm{followed} \mathrm{by} 0.5 \%$ & 20.8 & 0.82 & {$[160]$} \\
Rice straw & $\begin{array}{c}\mathrm{H}_{2} \mathrm{O}_{2}(\mathrm{pH} 11.5) \\
0.25 \mathrm{M} \mathrm{NaOH}(1: 25 \mathrm{w} / \mathrm{v})\end{array}$ & $18.6 \mathrm{~b}$ & $/$ & {$[176]$} \\
\hline
\end{tabular}

\subsection{Enzymatic extraction:}

In order to extract AXs from cereals, enzymatic techniques are often used. The most common enzyme family used for isolating AXs are the GH 11 endo- $\beta-(1,4)-$ xylanases $[25,161,178]$. Endoxylanases attack the xylan backbone, penetrating the cell wall and cleaving the internal $\beta-(1,4)$ linkages, a solubilizing portion of WUAX, aiding extraction $[27,115,179]$. Table 4 shows AXs' extraction yield from some cereals and cereal by-products by enzymatic extraction.

Comparing the extraction yields of enzyme treatments and alkaline treatments shows lower extraction yields of AXs from the enzyme treatments, for example, the extraction yield from de-starched wheat bran extracted with xylanase is $12.4 \%$ (Table 4), lower than that achieved with alkaline sodium hydroxide at $34.3 \%$. Zhang et al. [165] suggested that the low extraction yield might be due to the existence of enzyme inhibitors and that the crystalline structure of lignocellulose might limit the hydrolysis. 
Table 4. AXs extraction yield from some cereals using enzymatic treatment.

\begin{tabular}{|c|c|c|c|c|}
\hline Sources & Extraction & Yield\% of AXs & Ara/Xyl & References \\
\hline $\begin{array}{c}\text { De-starched } \\
\text { wheat bran }\end{array}$ & Xylanase 150 units, lab-scale & 12.4 & 0.56 & {$[6]$} \\
\hline $\begin{array}{c}\text { De-starched } \\
\text { wheat bran }\end{array}$ & $\begin{array}{c}\text { Pentopan mono BG 0.75\%, lab- } \\
\text { scale }\end{array}$ & 15.28 & NA & {$[180]$} \\
\hline Corn bran & $\begin{array}{c}\text { E-XYLNP 1500 U/mg from } \\
\text { Neocallimastix Patriciarum, lab } \\
\text { scale }\end{array}$ & 88.1 & 0.89 & {$[160]$} \\
\hline Rye bran & $\begin{array}{c}\text { Thermostable xylanase } \\
\text { RmXyn10A from Rhodothermus } \\
\text { marinus }\end{array}$ & $41-53$ & 0.38 & {$[181]$} \\
\hline \multirow{2}{*}{ Rye flour } & $\begin{array}{c}\text { 20 U } \beta \text {-glucosidase, 250 U (1-3,1- } \beta \text {-glucan 4-glucano-hydrolase } \\
\text { and 400 U amyloglucosidase, lab } \\
\text { scale }\end{array}$ & 1.08 & 0.5 & {$[43]$} \\
\hline
\end{tabular}

Although, the extraction yield using enzyme hydrolysis is not as high as the alkaline extraction, the action of alkaline solutions is not environmentally friendly as it produces hazardous waste and it might release the ferulic acid due to the breaking of the ester bond between AXs and the ferulic acid side chain, resulting in loss of antioxidant functionality [6]. Ferulic acid is known for its low solubility in water [179]. Zhou et al. [6] indicated that AXs extracted with enzymes have a higher ferulic acid content and it enhances the immune response more than AXs extracted with alkaline in an in vivo trial. 


\subsection{Mechanical extraction:}

There are several mechanical technologies have been studied as pre-treatments to improve the extraction yield of dietary fiber in general and specifically AXs. These include techniques such as microwave irradiation and extrusion [182-184].

\subsubsection{Microwave-assisted extraction:}

Microwave irradiation has been investigated as a technique to improve the extractability of hemicelluloses. There are several advantages of using microwave irradiation in the extraction of AXs, which are the ability to reach high temperatures and shorter extraction times [185, 186]. Microwave irradiation causes vibration between molecules, which potentially ruptures bonds. Rose and Inglett [183] optimized the processing conditions for AX extraction from maize; it was found that $50 \%$ of the AXs could be extracted at $200^{\circ} \mathrm{C}$ for 2 min or $180^{\circ} \mathrm{C}$ for 10 min. It was also reported that a combined microwave/pressure treatment of corn pericarp increased the extraction yield of AXs to $70.8 \%$ of total carbohydrates, consisting mainly of xylo-oligosaccharides. This high extraction rate can be achieved under pressurized water at $170.5^{\circ} \mathrm{C}$, solid:liquid ratio $1: 20(\mathrm{~g} / \mathrm{ml}), 2 \mathrm{~min}$ to reach operating temperature and $16 \mathrm{~min}$ heating time respectively [187]. Moreover, Coelho et al. [186] have reported that the microwaveassisted extraction of brewers' spent grain (BSG) has increased the extraction yield of AXs from 0.4 to $17 \%$ at 140 and $210^{\circ} \mathrm{C}$ respectively. The higher extraction yield achieved at the highest temperature could be related to the desertification, depolymerization and debranching of AXs complex material [186].

\subsubsection{Extrusion pre-treatment:}

Extrusion cooking is a valuable short-time, shear force, high-temperature, high pressure, processing technique, which has been used since the 1930s for the production of textured foods, 
ready-to-eat snacks, baby foods and breakfast cereals [188, 189]. Extrusion cooking improves the bioavailability of nutrients and the digestibility of protein and starch in comparison to other conventional cooking techniques [188, 190, 191].

Extrusion cooking technology has been used as a pre-treatment to extract hemicelluloses and increase the solubility of dietary fiber from wheat bran, pea hulls, lemon fiber, waxy barley and corn fiber [23, 192-195]. Wang et al. [196] have reported that there is a significant increase in soluble dietary fiber from $1.25 \%$ in raw whole wheat grain to $2.19 \%$ in samples extruded at $400 \mathrm{rpm}$. Moreover, a higher increase in solubility was reported from $1.75 \%$ in raw samples to $2.47 \%$ in extruded wheat bran samples at $400 \mathrm{rpm}$ [196]. Zhang et al. [28] have investigated the effect of temperature changes on dietary fiber solubility of oat bran. They reported that at a fixed screw-speed of $50 \mathrm{rpm}$ and $10 \%$ feed moisture, the solubility of dietary fiber increased from $9.9 \%$ to $14.2 \%$ when the temperature was increased from $100^{\circ} \mathrm{C}$ to $140^{\circ} \mathrm{C}$ [28].

However, there are conflicting findings on the effect of extrusion on the solubility of dietary fiber. Camire et al. [197], reported that at a constant screw-speed of $300 \mathrm{rpm}$, the solubility of dietary fiber from potato peels decreased from $4.69 \%$ (at $104^{\circ} \mathrm{C}$ barrel temperature and $31 \%$ feed moisture) to $3.75 \%$ (at $143^{\circ} \mathrm{C}$ barrel temperature and $36 \%$ feed moisture). In addition, Zeitoun et al. [184] compared twin-screw extrusion and stirred reactor extraction for hemicellulose extraction from wheat bran. She reported that extrusion pre-processing decreased the soluble hemicellulose from $59 \%$, using a stirred reactor, to $24 \%$. There are conflicting findings about the extrusion effect on dietary fiber/AXs solubility, which are summarized in Table 5.

Interestingly, extrusion not only has an effect on the solubility of dietary fiber, it also has an effect on molecular weight. The effect of extrusion on molecular weight has been investigated by Ralet et al. [198] who found that extrusion cooking reduced the molecular weight (Mw) of 
hemicelluloses extracted from sugar beet pulp fiber resulting in an increase in water solubility.

In another study, Margareta and Nyman [199] reported that extrusion of vegetables reduces the dietary fiber Mw, which was suggested to be due to the breaking of dietary fiber glyosidic bonds, resulting in depolymerization of the dietary fiber.

Reducing the molecular weight of the AXs not only increases their solubility in water but also increases their biological health benefits [115]. Recently, pronounced effects of low Mw AXs $(66 \mathrm{kDa})$ have been observed to have a higher prebiotic stimulation in an in vitro study when compared to higher Mw AXs [200]. Modification of the molecular characteristics of AXs such as $\mathrm{Mw}$ is important to achieve the optimum prebiotic, anti-tumor activities and immune stimulation [115].

Table 5. Main findings of the effect of extrusion of dietary fiber and AXs solubility.

\begin{tabular}{|c|c|c|c|}
\hline Food Source & Extrusion conditions & DF/ AXs change & References \\
\hline Corn fiber & $\begin{array}{l}\text { Twin-screw extruder, L/D ratio } \\
24: 1,3.0 \mathrm{~mm} \text { die diameter, } \\
\text { moisture; } 30,40 \text { and } 50 \% \text {, fixed } \\
\text { screw-speed } 200 \mathrm{rpm} \text { and feed } \\
\text { rate } 9 \mathrm{~kg} / \mathrm{h}\end{array}$ & $\begin{array}{c}\text { Soluble AX increased from } 463 \mathrm{~g} / \mathrm{kg} \text { to } \\
530 \mathrm{~g} / \mathrm{kg} \text { and } 586.3 \mathrm{~g} / \mathrm{kg} \text { at } 30 \text { and } 40 \% \\
\text { moisture }\end{array}$ & [195] \\
\hline $\begin{array}{l}\text { Wheat straw } \\
\text { and wheat } \\
\text { bran }\end{array}$ & $\begin{array}{l}\text { Twin-screw extruder, barrel } \\
\text { length } 1.6 \mathrm{~m} \text {, liquid/ solid ratio } 7 \text {, } \\
\text { feed rate } 13.8 \mathrm{~kg} / \mathrm{h} \text {, screw-speed } \\
150 \mathrm{rpm} \text { and fixed temperature at } \\
50^{\circ} \mathrm{C}\end{array}$ & $\begin{array}{l}\text { Hemicellulose extraction yield decreased } \\
\text { from } 59 \% \text { using stirred reactor to } 24 \% \\
\text { using an extruder. Xylan } \% \text { decreased } \\
\text { from } 76 \% \text { using stirred reactor to } 53 \% \\
\text { using extruder }\end{array}$ & [184] \\
\hline $\begin{array}{l}\text { Rice bran, } \\
\text { oat bran, and } \\
\text { wheat bran }\end{array}$ & $\begin{array}{l}\text { Twin-screw extruder, barrel } \\
\text { diameter } 62.2 \mathrm{~mm} \text {, fixed } \\
\text { temperature } 160^{\circ} \mathrm{C} \text {, feed rate } 68 \\
\mathrm{~kg} / \mathrm{h} \text { for oat and rice bran and } \\
51.25 \mathrm{~kg} / \mathrm{h} \text { for wheat bran, } \\
\text { screw-speeds } 50,70 \text { and } 100 \mathrm{rpm}\end{array}$ & $\begin{array}{c}\text { In oat bran, soluble DF increased from } \\
3.45 \% \mathrm{WE} \text { to } 5.46,5.24 \text { and } 4.58 \% \text { at } 50 \text {, } \\
70 \text { and } 100 \mathrm{rpm} \text { respectively. In rice bran, } \\
\text { solubility increased from } 2.0 \% \text { to } 2.5,2.33 \\
\text { and } 2.01 \% \text { using screw-speeds at } 50,70 \\
\text { and } 100 \mathrm{rpm} \text {. In wheat bran, increasing in } \\
\text { solubility from } 3.11 \% \text { to } 3.45 \text { and } 3.35 \% \text { at } \\
70 \text { and } 100 \mathrm{rpm} \text { while there was a decrease } \\
\text { at } 50 \mathrm{rpm} \text { to } 2.97 \%\end{array}$ & {$[201]$} \\
\hline $\begin{array}{l}\text { Whole wheat } \\
\text { and } \\
\text { germinated } \\
\text { wheat }\end{array}$ & $\begin{array}{l}\text { Twin-screw extruder with } \mathrm{CO}_{2} \\
\text { injection, } \mathrm{L} / \mathrm{D} \text { ratio } 24: 1 \text {, and die } \\
\text { diameter } 3.00 \mathrm{~mm} \text {, extrusion } \\
\text { carried out at } 90{ }^{\circ} \mathrm{C} \text { and } 130^{\circ} \mathrm{C} \text {, } \\
\text { screw-speeds were } 150 \text { and } 200\end{array}$ & $\begin{array}{l}\text { AXs solubility decreased from } 2.37 \text { in } \\
\text { whole wheat to } 1.91 \text { and } 1.65 \% \text { at } 150 \text { and } \\
200 \text { rpm screw-speed respectively. In } \\
\text { germinated wheat solubility decreased as }\end{array}$ & [195] \\
\hline
\end{tabular}




\begin{tabular}{|l|l|c|c|}
\hline & $\begin{array}{l}\text { rpm at constant moisture feed at } \\
30 \% . \mathrm{CO}_{2} \text { injection rate was 500 } \\
\mathrm{ml} / \mathrm{min} \text { and inlet pressure 20 } \\
\mathrm{MPa}\end{array}$ & $\begin{array}{r}\text { well from } 2.64 \text { to } 2.28 \text { and } 2.09 \% \text { at } 150 \\
\text { and } 200 \mathrm{rpm} \text { respectively }\end{array}$ & \\
\hline Wheat bran & $\begin{array}{l}\text { Twin-screw extruder with a } \\
\text { screw diameter of } 57 \mathrm{~mm}, \mathrm{~L} / \mathrm{D} \\
\text { ratio } 24: 1, \text { moisture } 20,25 \text { and } \\
30 \%, \text { die temperature 165, 175 } \\
\text { and } 185^{\circ} \mathrm{C} \text {, screw-speeds at } 180,\end{array}$ & $\begin{array}{c}\text { The solubility of dietary fibre at } 175^{\circ} \mathrm{C} \\
\text { temperature, } 25 \% \text { moisture and } 200 \mathrm{rpm} \\
\text { screw-speed was } 11.75 \% \text { in comparison } \\
\text { with } 2.54 \% \text { for untreated wheat bran }\end{array}$ & [202] \\
\hline 190 and 200 rpm. & & \\
\hline
\end{tabular}

WE: without extrusion, DF: dietary fiber.

\section{Conclusions:}

AXs are important food additives due to their several health benefits, including their beneficial effects on postprandial glucose response, lipid and cholesterol metabolism, immune response, oxidative stress and viremia. Numerous extraction methods have been applied to increase the extractability of AXs from different sources, including alkaline, enzymatic and mechanical treatments. The alkaline and the mechanical extraction methods have been reported to give the highest yield of AXs from different cereals. However, alkaline extraction has been reported to affect the molecular structure of AXs due to the disruption of cross-linkages, resulting in different molecular structures in WUAX more than those which would occur naturally, which in turn results in different functional characteristics. Moreover, the action of alkaline solutions is not environmentally friendly as it produces hazardous waste and it might release the ferulic acid due to the breaking of the ester bond between AXs and the ferulic acid side chain, resulting in loss of antioxidant functionality. The enzymatic treatment of AXs provides lower extraction yields in comparison with the alkaline treatment, yet it does not produce such hazardous wastes as the alkaline treatment does. The use of mechanical methods to improve the extractability of AXs has proved its efficiency in comparison with the alkaline extraction and has been shown to be more environment friendly. In summary, research studies show that the method of extraction has a strong influence on the extraction yields of AXs. Hence, future studies should 
focus on optimizing the extraction methods of AXs, which then can be used as a food enhancer. In addition, further studies are needed to delineate the exact mechanisms underlying the beneficial therapeutic effects of AXs.

\section{Conflicts of interest:}

The authors have no conflicts of interest to disclose. 


\section{References:}

[1] P. Comino, H. Collins, J. Lahnstein, M.J. Gidley, Effects of diverse food processing conditions on the structure and solubility of wheat, barley and rye endosperm dietary fibre, Journal of Food Engineering 169 (2016) 228-237.

[2] J. Ma, L. Adler, G. Srzednicki, J. Arcot, Quantitative determination of non-starch polysaccharides in foods using Gas Chromatography with flame ionization detection, Food Chem. 220 (2017) 100-107.

[3] B. Mohan, N. Malleshi, T. Koseki, Physico-chemical characteristics and non-starch polysaccharide contents of Indica and Japonica brown rice and their malts, LWT-Food Science and Technology 43(5) (2010) 784-791.

[4] X. Zhao, C. Dong, Extracting xylooligosaccharides in wheat bran by screening and cellulase assisted enzymatic hydrolysis, Int. J. Biol. Macromol. 92 (2016) 748-752.

[5] E. Haile, M. Gicheha, F.K. Njonge, G. Asgedom, Determining Nutritive Value of Cereal Crop Residues and Lentil (Lens esculanta) Straw for Ruminants, Sciences 7 (2017) 19-29. [6] S. Zhou, X. Liu, Y. Guo, Q. Wang, D. Peng, L. Cao, Comparison of the immunological activities of arabinoxylans from wheat bran with alkali and xylanase-aided extraction, Carbohydrate Polymers 81(4) (2010) 784-789.

[7] M. Messia, T. Candigliota, E. De Arcangelis, E. Marconi, ARABINOXYLANS AND $\beta$ GLUCANS ASSESSMENT IN CEREALS, Italian Journal of Food Science 29(1) (2017).

[8] M.S. Izydorczyk, C.G. Biliaderis, Cereal arabinoxylans: advances in structure and physicochemical properties, Carbohydrate Polymers 28(1) (1995) 33-48.

[9] M.P. Yadav, M.S. Kale, K.B. Hicks, K. Hanah, Isolation, characterization and the functional properties of cellulosic arabinoxylan fiber isolated from agricultural processing by-products, agricultural residues and energy crops, Food Hydrocolloids 63 (2017) 545-551.

[10] M. Izydorczyk, C. Biliaderis, W. Bushuk, Comparison of the structure and composition of water-soluble pentosans from different wheat varieties, Cereal chemistry (USA) (1991).

[11] R. Houben, C. De Ruijter, K. Brunt, Determination of the pentosan content of wheat products by hydrolysis, glucose oxidase treatment and analysis by HPAEC/PAD, Journal of cereal science 26(1) (1997) 37-46.

[12] G. Gartaula, S. Dhital, D. Pleming, M.J. Gidley, Isolation of wheat endosperm cell walls: Effects of non-endosperm flour components on structural analyses, Journal of Cereal Science 74 (2017) 165-173.

[13] S. Hashimoto, M. Shogren, Y. Pomeranz, Cereal pentosans: their estimation and significance. I. Pentosans in wheat and milled wheat products, Cereal chemistry (USA) (1987).

[14] M. Choct, Feed non-starch polysaccharides: chemical structures and nutritional significance, Feed milling international 191(June issue) (1997) 13-26.

[15] S.C. Fry, Primary cell wall metabolism: tracking the careers of wall polymers in living plant cells, New phytologist 161(3) (2004) 641-675.

[16] C. Courtin, H. Van den Broeck, J. Delcour, Determination of reducing end sugar residues in oligo-and polysaccharides by gas-liquid chromatography, J. Chromatogr. A 866(1) (2000) 97-104.

[17] J. Roubroeks, R. Andersson, P. Åman, Structural features of $(1 \rightarrow 3),(1 \rightarrow 4)-\beta$-D-glucan and arabinoxylan fractions isolated from rye bran, Carbohydrate Polymers 42(1) (2000) 311. 
[18] M. Mendis, E. Leclerc, S. Simsek, Arabinoxylan hydrolyzates as immunomodulators in Caco-2 and HT-29 colon cancer cell lines, Food Funct. (2017).

[19] M. Mendis, E. Leclerc, S. Simsek, Arabinoxylan hydrolyzates as immunomodulators in lipopolysaccharide-induced RAW264. 7 macrophages, Food Funct. 7(7) (2016) 3039-3045.

[20] M.J. Hopkins, H.N. Englyst, S. Macfarlane, E. Furrie, G.T. Macfarlane, A.J. McBain, Degradation of cross-linked and non-cross-linked arabinoxylans by the intestinal microbiota in children, Appl. Environ. Microbiol. 69(11) (2003) 6354-6360.

[21] L. Yu, G.E. Yakubov, W. Zeng, X. Xing, J. Stenson, V. Bulone, J.R. Stokes, Multi-layer mucilage of Plantago ovata seeds: Rheological differences arise from variations in arabinoxylan side chains, Carbohydrate Polymers 165 (2017) 132-141.

[22] O. Kosik, S.J. Powers, A. Chatzifragkou, P.C. Prabhakumari, D. Charalampopoulos, L. Hess, J. Brosnan, P.R. Shewry, A. Lovegrove, Changes in the arabinoxylan fraction of wheat grain during alcohol production, Food Chem. 221 (2017) 1754-1762.

[23] T. Vasanthan, J. Gaosong, J. Yeung, J. Li, Dietary fiber profile of barley flour as affected by extrusion cooking, Food Chem. 77(1) (2002) 35-40.

[24] Y. Li, Y. Zhu, R. Liang, C. Yang, Synthesis and antioxidant properties of caffeic acid corn bran arabinoxylan esters, Int. J. Cosmet. Sci. (2017).

[25] J.A. Walker, S. Pattathil, L.F. Bergeman, E.T. Beebe, K. Deng, M. Mirzai, T.R. Northen, M.G. Hahn, B.G. Fox, Determination of glycoside hydrolase specificities during hydrolysis of plant cell walls using glycome profiling, Biotechnology for Biofuels 10(1) (2017) 31. [26] L. Cao, X. Liu, T. Qian, G. Sun, Y. Guo, F. Chang, S. Zhou, X. Sun, Antitumor and immunomodulatory activity of arabinoxylans: A major constituent of wheat bran, International Journal of Biological Macromolecules 48(1) (2011) 160-164.

[27] K. Swennen, C.M. Courtin, G.C. Lindemans, J.A. Delcour, Large-scale production and characterisation of wheat bran arabinoxylooligosaccharides, J. Sci. Food Agric. 86(11) (2006) 1722-1731.

[28] M. Zhang, X. Bai, Z. Zhang, Extrusion process improves the functionality of soluble dietary fiber in oat bran, Journal of Cereal Science 54(1) (2011) 98-103.

[29] C. Liu, Y. Zhang, W. Liu, J. Wan, W. Wang, L. Wu, N. Zuo, Y. Zhou, Z. Yin, Preparation, physicochemical and texture properties of texturized rice produce by improved extrusion cooking technology, Journal of Cereal Science 54(3) (2011) 473-480.

[30] S.-J. Jeon, S. Singkhornart, G.-H. Ryu, The Effect of Extrusion Conditions on Waterextractable Arabinoxylans from Corn Fiber, Preventive nutrition and food science 19(2) (2014) 124.

[31] Y.-S. Choi, J.-K. Lee, M.-G. Lee, S. Lee, H.-Y. Jeong, H. Kang, Splenic T cell and intestinal IgA responses after supplementation of soluble arabinoxylan-enriched wheat bran in mice, Journal of Functional Foods 28 (2017) 246-253.

[32] W. Li, S. Zhang, C. Smith, The molecular structure features-immune stimulatory activity of arabinoxylans derived from the pentosan faction of wheat flour, Journal of Cereal Science 62 (2015) 81-86.

[33] P. Zhang, J.L. Wampler, A.K. Bhunia, K.M. Burkholder, J.A. Patterson, R.L. Whistler, Effects of arabinoxylans on activation of murine macrophages and growth performance of broiler chicks, Cereal Chem. 81(4) (2004) 511-514.

[34] Q. Liu, X. Cao, X. Zhuang, W. Han, W. Guo, J. Xiong, X. Zhang, Rice bran polysaccharides and oligosaccharides modified by Grifola frondosa fermentation: Antioxidant activities and effects on the production of NO, Food Chem. 223 (2017) 49-53. 
[35] M. Ghoneum, M. Matsuura, Augmentation of macrophage phagocytosis by modified arabinoxylan rice bran (MGN-3/biobran), Int. J. Immunopathol. Pharmacol. 17(3) (2004) 283-292.

[36] H. Kim, H.-D. Hong, K.-S. Shin, Structure elucidation of an immunostimulatory arabinoxylan-type polysaccharide prepared from young barley leaves (Hordeum vulgare L.), Carbohydrate Polymers 157 (2017) 282-293.

[37] S. Qiu, M.P. Yadav, L. Yin, Characterization and functionalities study of hemicellulose and cellulose components isolated from sorghum bran, bagasse and biomass, Food Chem. (2017).

[38] D. JMares, B. Stone, Studies on wheat endosperm I. Chemical composition and ultrastructure of the cell walls, Aust. J. Biol. Sci. 26(4) (1973) 793-812.

[39] V. Malathi, G. Devegowda, In vitro evaluation of nonstarch polysaccharide digestibility of feed ingredients by enzymes, Poult. Sci. 80(3) (2001) 302-305.

[40] W. Yang, Z. Jiang, L. Liu, Y. Lin, L. Wang, S. Zhou, The effect of pentosanase on the solubilisation and degradation of arabinoxylan extracted from whole and refined wheat flour, J. Sci. Food Agric. 97(3) (2017) 1034-1041.

[41] L. Saulnier, P.-E. Sado, G. Branlard, G. Charmet, F. Guillon, Wheat arabinoxylans: exploiting variation in amount and composition to develop enhanced varieties, Journal of Cereal Science 46(3) (2007) 261-281.

[42] W.F. Broekaert, C.M. Courtin, K. Verbeke, T. Van de Wiele, W. Verstraete, J.A. Delcour, Prebiotic and other health-related effects of cereal-derived arabinoxylans, arabinoxylanoligosaccharides, and xylooligosaccharides, Crit. Rev. Food Sci. Nutr. 51(2) (2011) 178-194. [43] G. Dervilly-Pinel, L. Rimsten, L. Saulnier, R. Andersson, P. Åman, Water-extractable arabinoxylan from pearled flours of wheat, barley, rye and triticale. Evidence for the presence of ferulic acid dimers and their involvement in gel formation, Journal of Cereal Science 34(2) (2001) 207-214.

[44] S. Zhang, W. Li, C. Smith, H. Musa, Cereal-derived arabinoxylans as biological response modifiers: extraction, molecular features, and immune-stimulating properties, Critical reviews in food science and nutrition 55(8) (2015) 1035-1052.

[45] J. Ordaz-Ortiz, L. Saulnier, Structural variability of arabinoxylans from wheat flour. Comparison of water-extractable and xylanase-extractable arabinoxylans, Journal of Cereal Science 42(1) (2005) 119-125.

[46] J. Lu, Y. Li, G. Gu, Z. Mao, Effects of molecular weight and concentration of arabinoxylans on the membrane plugging, J. Agric. Food Chem. 53(12) (2005) 4996-5002. [47] M. Izydorczyk, L. Macri, A. MacGregor, Structure and physicochemical properties of barley non-starch polysaccharides - I. Water-extractable $\beta$-glucans and arabinoxylans, Carbohydrate Polymers 35(3-4) (1998) 249-258.

[48] M. Cyran, C.M. Courtin, J.A. Delcour, Structural features of arabinoxylans extracted with water at different temperatures from two rye flours of diverse breadmaking quality, J. Agric. Food Chem. 51(15) (2003) 4404-4416.

[49] M.S. Iqbal, J. Akbar, M.A. Hussain, S. Saghir, M. Sher, Evaluation of hot-water extracted arabinoxylans from ispaghula seeds as drug carriers, Carbohydrate polymers 83(3) (2011) 1218-1225.

[50] J. Wang, B. Sun, Y. Liu, H. Zhang, Optimisation of ultrasound-assisted enzymatic extraction of arabinoxylan from wheat bran, Food Chem. 150 (2014) 482-488. 
[51] K. Moers, I. Celus, K. Brijs, C.M. Courtin, J.A. Delcour, Endoxylanase substrate selectivity determines degradation of wheat water-extractable and water-unextractable arabinoxylan, Carbohydr. Res. 340(7) (2005) 1319-1327.

[52] H. Gruppen, F. Kormelink, A. Voragen, Water-unextractable cell wall material from wheat flour. 3. A structural model for arabinoxylans, Journal of cereal science 18(2) (1993) 111-128.

[53] World Health Organization, S. Department of Noncommunicable Disease, Definition, diagnosis and classification of diabetes mellitus and its complications : report of a WHO consultation. Part 1, Part 1, (1999).

[54] American Diabetes Association, Diagnosis and classification of diabetes mellitus, Diabetes care 33 (2010) 62-9.

[55] Y. Wu, Y. Ding, Y. Tanaka, W. Zhang, Risk factors contributing to type 2 diabetes and recent advances in the treatment and prevention, International journal of medical sciences 11(11) (2014) 1185-200.

[56] International Diabetes Federation, IDF Diabetes Atlas, 2015.

http://www.idf.org/diabetesatlas.

[57] Z.X. Lu, K.Z. Walker, J.G. Muir, T. Mascara, K. O'Dea, Arabinoxylan fiber, a byproduct of wheat flour processing, reduces the postprandial glucose response in normoglycemic subjects, The American journal of clinical nutrition 71(5) (2000) 1123-8.

[58] M. Mohlig, C. Koebnick, M.O. Weickert, W. Lueder, B. Otto, J. Steiniger, M. Twilfert, F. Meuser, A.F. Pfeiffer, H.J. Zunft, Arabinoxylan-enriched meal increases serum ghrelin levels in healthy humans, Hormone and metabolic research $=$ Hormon- und Stoffwechselforschung = Hormones et metabolisme 37(5) (2005) 303-8.

[59] A. Giulia Falchi, I. Grecchi, C. Muggia, G. Palladini, S. Perlini, Effects of a Bioavailable Arabinoxylan-enriched White Bread Flour on Postprandial Glucose Response in Normoglycemic Subjects, Journal of dietary supplements 13(6) (2016) 626-33.

[60] E.V. Boll, L.M. Ekstrom, C.M. Courtin, J.A. Delcour, A.C. Nilsson, I.M. Bjorck, E.M. Ostman, Effects of wheat bran extract rich in arabinoxylan oligosaccharides and resistant starch on overnight glucose tolerance and markers of gut fermentation in healthy young adults, European journal of nutrition 55(4) (2016) 1661-70.

[61] A.L. Garcia, B. Otto, S.C. Reich, M.O. Weickert, J. Steiniger, A. Machowetz, N.N. Rudovich, M. Mohlig, N. Katz, M. Speth, F. Meuser, J. Doerfer, H.J. Zunft, A.H. Pfeiffer, C. Koebnick, Arabinoxylan consumption decreases postprandial serum glucose, serum insulin and plasma total ghrelin response in subjects with impaired glucose tolerance, European journal of clinical nutrition 61(3) (2007) 334-41.

[62] A.L. Garcia, J. Steiniger, S.C. Reich, M.O. Weickert, I. Harsch, A. Machowetz, M. Mohlig, J. Spranger, N.N. Rudovich, F. Meuser, J. Doerfer, N. Katz, M. Speth, H.J. Zunft, A.H. Pfeiffer, C. Koebnick, Arabinoxylan fibre consumption improved glucose metabolism, but did not affect serum adipokines in subjects with impaired glucose tolerance, Hormone and metabolic research $=$ Hormon - und Stoffwechselforschung $=$ Hormones et metabolisme 38(11) (2006) 761-6.

[63] H. Hanai, M. Ikuma, Y. Sato, T. lida, Y. Hosoda, I. Matsushita, A. Nogaki, M. Yamada, E. Kaneko, Long-term effects of water-soluble corn bran hemicellulose on glucose tolerance in obese and non-obese patients: improved insulin sensitivity and glucose metabolism in obese subjects, Bioscience, biotechnology, and biochemistry 61(8) (1997) 1358-61. 
[64] S.S. Cho, L. Qi, G.C. Fahey, Jr., D.M. Klurfeld, Consumption of cereal fiber, mixtures of whole grains and bran, and whole grains and risk reduction in type 2 diabetes, obesity, and cardiovascular disease, The American journal of clinical nutrition 98(2) (2013) 594-619.

[65] C. Eelderink, M. Schepers, T. Preston, R.J. Vonk, L. Oudhuis, M.G. Priebe, Slowly and rapidly digestible starchy foods can elicit a similar glycemic response because of differential tissue glucose uptake in healthy men, The American journal of clinical nutrition 96(5) (2012) 1017-24.

[66] C. Heidemann, M.B. Schulze, O.H. Franco, R.M. van Dam, C.S. Mantzoros, F.B. Hu, Dietary patterns and risk of mortality from cardiovascular disease, cancer, and all causes in a prospective cohort of women, Circulation 118(3) (2008) 230-7.

[67] B. Yao, H. Fang, W. Xu, Y. Yan, H. Xu, Y. Liu, M. Mo, H. Zhang, Y. Zhao, Dietary fiber intake and risk of type 2 diabetes: a dose-response analysis of prospective studies, European journal of epidemiology 29(2) (2014) 79-88.

[68] K.C. Maki, A.K. Phillips, Dietary substitutions for refined carbohydrate that show promise for reducing risk of type 2 diabetes in men and women, J Nutr 145(1) (2015) 159s$163 \mathrm{~s}$.

[69] D.E. Threapleton, D.C. Greenwood, C.E. Evans, C.L. Cleghorn, C. Nykjaer, C. Woodhead, J.E. Cade, C.P. Gale, V.J. Burley, Dietary fibre intake and risk of cardiovascular disease: systematic review and meta-analysis, BMJ (Clinical research ed.) 347 (2013) f6879. [70] A.G. Schioldan, S. Gregersen, S. Hald, A. Bjornshave, M. Bohl, B. Hartmann, J.J. Holst, H. Stodkilde-Jorgensen, K. Hermansen, Effects of a diet rich in arabinoxylan and resistant starch compared with a diet rich in refined carbohydrates on postprandial metabolism and features of the metabolic syndrome, European journal of nutrition (2017).

[71] Z.X. Lu, K.Z. Walker, J.G. Muir, K. O'Dea, Arabinoxylan fibre improves metabolic control in people with Type II diabetes, European journal of clinical nutrition 58(4) (2004) 621-8. [72] M.L. Hartvigsen, P.B. Jeppesen, H.N. Laerke, E.N. Njabe, K.E. Knudsen, K. Hermansen, Concentrated arabinoxylan in wheat bread has beneficial effects as rye breads on glucose and changes in gene expressions in insulin-sensitive tissues of Zucker diabetic fatty (ZDF) rats, J Agric Food Chem 61(21) (2013) 5054-63.

[73] L.N. Malunga, P. Eck, T. Beta, Inhibition of Intestinal \&\#x3b1;-Glucosidase and Glucose Absorption by Feruloylated Arabinoxylan Mono- and Oligosaccharides from Corn Bran and Wheat Aleurone, Journal of Nutrition and Metabolism 2016 (2016) 9.

[74] D.J. Jenkins, T.M. Wolever, A.R. Leeds, M.A. Gassull, P. Haisman, J. Dilawari, D.V. Goff, G.L. Metz, K.G. Alberti, Dietary fibres, fibre analogues, and glucose tolerance: importance of viscosity, British medical journal 1(6124) (1978) 1392-4.

[75] S. Dhital, G. Dolan, J.R. Stokes, M.J. Gidley, Enzymatic hydrolysis of starch in the presence of cereal soluble fibre polysaccharides, Food \& function 5(3) (2014) 579-86.

[76] R. Giacco, G. Costabile, G. Della Pepa, G. Anniballi, E. Griffo, A. Mangione, P. Cipriano, D. Viscovo, G. Clemente, R. Landberg, G. Pacini, A.A. Rivellese, G. Riccardi, A whole-grain cereal-based diet lowers postprandial plasma insulin and triglyceride levels in individuals with metabolic syndrome, Nutrition, metabolism, and cardiovascular diseases : NMCD 24(8) (2014) 837-44.

[77] H. Chen, Y. Fu, X. Jiang, D. Li, W. Qin, Q. Zhang, D. Lin, Y. Liu, C. Tan, Z. Huang, Y. Liu, D. Chen, Arabinoxylan activates lipid catabolism and alleviates liver damage in rats induced by high-fat diet, J Sci Food Agric (2017).

[78] P. Gunness, B.A. Williams, W.J. Gerrits, A.R. Bird, O. Kravchuk, M.J. Gidley, Circulating triglycerides and bile acids are reduced by a soluble wheat arabinoxylan via modulation of 
bile concentration and lipid digestion rates in a pig model, Mol Nutr Food Res 60(3) (2016) 642-51.

[79] H.W. Lopez, M.A. Levrat, C. Guy, A. Messager, C. Demigne, C. Remesy, Effects of soluble corn bran arabinoxylans on cecal digestion, lipid metabolism, and mineral balance ( $\mathrm{Ca}, \mathrm{Mg}$ ) in rats, J Nutr Biochem 10(9) (1999) 500-9.

[80] L.T. Tong, K. Zhong, L. Liu, J. Qiu, L. Guo, X. Zhou, L. Cao, S. Zhou, Effects of dietary wheat bran arabinoxylans on cholesterol metabolism of hypercholesterolemic hamsters, Carbohydrate polymers 112 (2014) 1-5.

[81] A. Adam, M.A. Levrat-Verny, H.W. Lopez, M. Leuillet, C. Demigne, C. Remesy, Whole wheat and triticale flours with differing viscosities stimulate cecal fermentations and lower plasma and hepatic lipids in rats, J Nutr 131(6) (2001) 1770-6.

[82] K. Sato, A. Ohuchi, S.H. Sook, M. Toyomizu, Y. Akiba, Changes in mRNA expression of 3hydroxy-3-methylglutaryl coenzyme $A$ reductase and cholesterol 7 alpha-hydroxylase in chickens, Biochim Biophys Acta 1630(2-3) (2003) 96-102.

[83] P. Van den Abbeele, P. Gerard, S. Rabot, A. Bruneau, S. El Aidy, M. Derrien, M. Kleerebezem, E.G. Zoetendal, H. Smidt, W. Verstraete, T. Van de Wiele, S. Possemiers, Arabinoxylans and inulin differentially modulate the mucosal and luminal gut microbiota and mucin-degradation in humanized rats, Environmental microbiology 13(10) (2011) 266780.

[84] P. Van den Abbeele, K. Venema, T. Van de Wiele, W. Verstraete, S. Possemiers, Different human gut models reveal the distinct fermentation patterns of Arabinoxylan versus inulin, J Agric Food Chem 61(41) (2013) 9819-27.

[85] S. Satta, A.M. Mahmoud, F.L. Wilkinson, M. Yvonne Alexander, S.J. White, The Role of Nrf2 in Cardiovascular Function and Disease, Oxidative Medicine and Cellular Longevity 2017 (2017) 18.

[86] V. Crespy, C. Morand, C. Besson, N. Cotelle, H. Vezin, C. Demigne, C. Remesy, The splanchnic metabolism of flavonoids highly differed according to the nature of the compound, American journal of physiology. Gastrointestinal and liver physiology 284(6) (2003) G980-8.

[87] Y. Okai, K. Higashi-Okai, Radical-scavenging activity of hot water extract of Japanese rice bran--association with phenolic acids, Journal of UOEH 28(1) (2006) 1-12.

[88] P. Yuwang, I. Sulaeva, J. Hell, U. Henniges, S. Bohmdorfer, T. Rosenau, B. Chitsomboon, S. Tongta, Phenolic compounds and antioxidant properties of arabinoxylan hydrolysates from defatted rice bran, J Sci Food Agric (2017).

[89] S.Y. Ou, G.M. Jackson, X. Jiao, J. Chen, J.Z. Wu, X.S. Huang, Protection against oxidative stress in diabetic rats by wheat bran feruloyl oligosaccharides, J Agric Food Chem 55(8) (2007) 3191-5.

[90] X. Yuan, J. Wang, H. Yao, F. Chen, Free radical-scavenging capacity and inhibitory activity on rat erythrocyte hemolysis of feruloyl oligosaccharides from wheat bran insoluble dietary fiber, LWT - Food Science and Technology 38(8) (2005) 877-883.

[91] Q. Lin, S. Ou, Q. Wen, In vitro antioxidant activity of feruloyl arabinose isolated from maize bran by acid hydrolysis, Journal of food science and technology 51(7) (2014) 1356-62. [92] J. Laranjinha, O. Vieira, V. Madeira, L. Almeida, Two related phenolic antioxidants with opposite effects on vitamin $\mathrm{E}$ content in low density lipoproteins oxidized by ferrylmyoglobin: consumption vs regeneration, Archives of biochemistry and biophysics 323(2) (1995) 373-81. 
[93] B.R. Veenashri, G. Muralikrishna, In vitro anti-oxidant activity of xylo-oligosaccharides derived from cereal and millet brans - A comparative study, Food Chemistry 126(3) (2011) 1475-1481.

[94] L.N. Malunga, T. Beta, Antioxidant Capacity of Water-Extractable Arabinoxylan from Commercial Barley, Wheat, and Wheat Fractions, Cereal Chemistry Journal 92(1) (2014) 2936.

[95] A. Bagdi, S. Tomoskozi, L. Nystrom, Hydroxyl radical oxidation of feruloylated arabinoxylan, Carbohydrate polymers 152 (2016) 263-270.

[96] J. Snelders, E. Dornez, J.A. Delcour, C.M. Courtin, Ferulic Acid content and appearance determine the antioxidant capacity of arabinoxylanoligosaccharides, J Agric Food Chem 61(42) (2013) 10173-82.

[97] P. Katapodis, M. Vardakou, E. Kalogeris, D. Kekos, B.J. Macris, P. Christakopoulos, Enzymic production of a feruloylated oligosaccharide with antioxidant activity from wheat flour arabinoxylan, European journal of nutrition 42(1) (2003) 55-60.

[98] H. Kikuzaki, M. Hisamoto, K. Hirose, K. Akiyama, H. Taniguchi, Antioxidant properties of ferulic acid and its related compounds, J Agric Food Chem 50(7) (2002) 2161-8.

[99] R.S. Rao, G. Muralikrishna, Water soluble feruloyl arabinoxylans from rice and ragi: changes upon malting and their consequence on antioxidant activity, Phytochemistry $67(1)$ (2006) 91-9.

[100] T. Ohta, S. Yamasaki, Y. Egashira, H. Sanada, Antioxidative Activity of Corn Bran Hemicellulose Fragments, Journal of Agricultural and Food Chemistry 42(3) (1994) 653-656. [101] T. Ishii, Structure and functions of feruloylated polysaccharides, Plant Science 127(2) (1997) 111-127.

[102] H. Zhang, J. Wang, Y. Liu, B. Sun, Wheat bran feruloyl oligosaccharides modulate the phase II detoxifying/antioxidant enzymes via Nrf2 signaling, Int J Biol Macromol 74 (2015) 150-4.

[103] A.M. Mahmoud, H.S. Al Dera, 18ß-Glycyrrhetinic acid exerts protective effects against cyclophosphamide-induced hepatotoxicity: Potential role of PPARY and Nrf2 upregulation, Genes \& nutrition 10(6) (2015) 1-13.

[104] A.M. Mahmoud, M.O. Germoush, M.F. Alotaibi, O.E. Hussein, Possible involvement of Nrf2 and PPARgamma up-regulation in the protective effect of umbelliferone against cyclophosphamide-induced hepatotoxicity, Biomed Pharmacother 86 (2017) 297-306. [105] A.M. Mahmoud, O.E. Hussein, W.G. Hozayen, S.M. Abd El-Twab, Methotrexate hepatotoxicity is associated with oxidative stress, and down-regulation of PPARgamma and Nrf2: Protective effect of 18beta-Glycyrrhetinic acid, Chem Biol Interact 270 (2017) 59-72. [106] A.M. Mahmoud, F.L. Wilkinson, A.M. Jones, J.A. Wilkinson, M. Romero, J. Duarte, M.Y. Alexander, A novel role for small molecule glycomimetics in the protection against lipidinduced endothelial dysfunction: Involvement of Akt/eNOS and Nrf2/ARE signaling, Biochim Biophys Acta 1861((1 Pt A)) (2017) 3311-3322.

[107] A.M. Mahmoud, F.L. Wilkinson, E.M. McCarthy, D. Moreno-Martinez, A. LangfordSmith, M. Romero, J. Duarte, M.Y. Alexander, Endothelial microparticles prevent lipidinduced endothelial damage via Akt/eNOS signaling and reduced oxidative stress, FASEB J 31(10) (2017) doi: 10.1096/fj.201601244RR. [Epub ahead of print].

[108] A.M. Mahmoud, S. Alqahtani, S.I. Othman, M.O. Germoush, O.E. Hussein, G. Al-Basher, J.S. Khim, M.A. Al-Qaraawi, H.M. Al-Harbi, A. Fadel, A.A. Allam, Commiphora molmol Modulates Glutamate-Nitric Oxide-cGMP and Nrf2/ARE/HO-1 Pathways and Attenuates 
Oxidative Stress and Hematological Alterations in Hyperammonemic Rats, Oxidative Medicine and Cellular Longevity 2017(ID 7369671) (2017) 15.

[109] A.M. Mahmoud, A.R. Zaki, M.E. Hassan, G. Mostafa-Hedeab, Commiphora molmol resin attenuates diethylnitrosamine/phenobarbital-induced hepatocarcinogenesis by modulating oxidative stress, inflammation, angiogenesis and Nrf2/ARE/HO-1 signaling, Chem Biol Interact 270 (2017) 41-50.

[110] A.M. Mahmoud, H.M. Mohammed, S.M. Khadrawy, S.R. Galaly, Hesperidin protects against chemically induced hepatocarcinogenesis via modulation of Nrf2/ARE/HO-1, PPARgamma and TGF-beta1/Smad3 signaling, and amelioration of oxidative stress and inflammation, Chem Biol Interact 277 (2017) 146-158.

[111] S. Zheng, H. Sanada, H. Dohi, S. Hirai, Y. Egashira, Suppressive effect of modified arabinoxylan from rice bran (MGN-3) on D-galactosamine-induced IL-18 expression and hepatitis in rats, Bioscience, biotechnology, and biochemistry 76(5) (2012) 942-6.

[112] K. Decker, D. Keppler, Galactosamine induced liver injury, Progress in liver diseases 4 (1972) 183-99.

[113] S. Zheng, S. Sugita, S. Hirai, Y. Egashira, Protective effect of low molecular fraction of MGN-3, a modified arabinoxylan from rice bran, on acute liver injury by inhibition of NFkappaB and JNK/MAPK expression, Int Immunopharmacol 14(4) (2012) 764-9.

[114] H. Salama, E. Medhat, M. Shaheen, A.N. Zekri, T. Darwish, M. Ghoneum, Arabinoxylan rice bran (Biobran) suppresses the viremia level in patients with chronic HCV infection: $A$ randomized trial, International journal of immunopathology and pharmacology 29(4) (2016) 647-653.

[115] W. Li, H. Hu, Q. Wang, C.S. Brennan, Molecular features of wheat endosperm arabinoxylan inclusion in functional bread, Foods 2(2) (2013) 225-237.

[116] D. Cholujova, J. Jakubikova, B. Czako, M. Martisova, L. Hunakova, J. Duraj, M. Mistrik, J. Sedlak, MGN-3 arabinoxylan rice bran modulates innate immunity in multiple myeloma patients, Cancer Immunology, Immunotherapy 62(3) (2013) 437-445.

[117] A. Pérez-Martínez, J. Valentín, L. Fernández, E. Hernández-Jiménez, E. López-Collazo, P. Zerbes, E. Schwörer, F. Nuñéz, I.G. Martín, H. Sallis, Arabinoxylan rice bran (MGN-

$3 /$ Biobran) enhances natural killer cell-mediated cytotoxicity against neuroblastoma in vitro and in vivo, Cytotherapy 17(5) (2015) 601-612.

[118] N.K. Badr El-Din, S.M. Abdel Fattah, D. Pan, L. Tolentino, M. Ghoneum, Chemopreventive Activity of MGN-3/Biobran Against Chemical Induction of Glandular Stomach Carcinogenesis in Rats and Its Apoptotic Effect in Gastric Cancer Cells, Integrative cancer therapies 15(4) (2016) NP26-NP34.

[119] N.K. Badr El-Din, D.A. Ali, M. Alaa El-Dein, M. Ghoneum, Enhancing the Apoptotic Effect of a Low Dose of Paclitaxel on Tumor Cells in Mice by Arabinoxylan Rice Bran (MGN3/Biobran), Nutrition and cancer 68(6) (2016) 1010-1020.

[120] N.K. Badr El-Din, E. Noaman, M. Ghoneum, In vivo tumor inhibitory effects of nutritional rice bran supplement MGN-3/Biobran on Ehrlich carcinoma-bearing mice, Nutrition and cancer 60(2) (2008) 235-244.

[121] M. Ghoneum, S. Agrawal, MGN-3/Biobran enhances generation of cytotoxic CD8+ T cells via upregulation of DEC-205 expression on dendritic cells, International journal of immunopathology and pharmacology 27(4) (2014) 523-530.

[122] A.B. Samuelsen, A. Rieder, S. Grimmer, T.E. Michaelsen, S.H. Knutsen, Immunomodulatory activity of dietary fiber: arabinoxylan and mixed-linked beta-glucan 
isolated from barley show modest activities in vitro, International journal of molecular sciences 12(1) (2011) 570-587.

[123] M. Ghoneum, A. Jewett, Production of tumor necrosis factor-alpha and interferongamma from human peripheral blood lymphocytes by MGN-3, a modified arabinoxylan from rice bran, and its synergy with interleukin-2 in vitro, Cancer detection and prevention 24(4) (1999) 314-324.

[124] D. Cholujova, J. Jakubikova, J. Sedlak, BioBran-augmented maturation of human monocytederived dendritic cells, Neoplasma 56(2) (2009) 89.

[125] M. Ghoneum, S. Agrawal, Activation of human monocyte-derived dendritic cells in vitro by the biological response modifier arabinoxylan rice bran (MGN-3/Biobran), International journal of immunopathology and pharmacology 24(4) (2011) 941-948. [126] M. Ghoneum, J. Brown, NK immunorestoration of cancer patients by MGN-3, a modified arabinoxylan rice bran (study of 32 patients followed up to four years), 6th International Congress on Anti-Aging and Bio-Medical Technologies, 1998.

[127] L. Wang, H. Zhang, X. Zhang, Z. Chen, Purification and identification of a novel heteropolysaccharide RBPS2a with anti-complementary activity from defatted rice bran, Food Chem 110(1) (2008) 150-5.

[128] Y. Hoshino, N. Hirashima, M. Nakanishi, T. Furuno, Inhibition of degranulation and cytokine production in bone marrow-derived mast cells by hydrolyzed rice bran, Inflammation research 59(8) (2010) 615-625.

[129] H.-Y. Fang, Y.-K. Chen, H.-H. Chen, S.-Y. Lin, Y.-T. Fang, Immunomodulatory effects of feruloylated oligosaccharides from rice bran, Food chemistry 134(2) (2012) 836-840. [130] L. Wang, Y. Li, L. Zhu, R. Yin, R. Wang, X. Luo, Y. Li, Y. Li, Z. Chen, Antitumor activities and immunomodulatory of rice bran polysaccharides and its sulfates in vitro, International journal of biological macromolecules 88 (2016) 424-432.

[131] M. Bermudez-Brito, N.M. Sahasrabudhe, C. Rösch, H.A. Schols, M.M. Faas, P. Vos, The impact of dietary fibers on dendritic cell responses in vitro is dependent on the differential effects of the fibers on intestinal epithelial cells, Molecular nutrition \& food research 59(4) (2015) 698-710.

[132] M.S. Prashanth, G. Muralikrishna, Arabinoxylan from finger millet (Eleusine coracana, v. Indaf 15) bran: purification and characterization, Carbohydrate polymers 99 (2014) 800807.

[133] M.S. Prashanth, R. Shruthi, G. Muralikrishna, Immunomodulatory activity of purified arabinoxylans from finger millet (Eleusine coracana, v. Indaf 15) bran, Journal of food science and technology 52(9) (2015) 6049-6054.

[134] J. Moza, H.S. Gujral, Influence of non-starchy polysaccharides on barley milling behavior and evaluating bioactive composition of milled fractions, Food Chem. 218 (2017) 137-143.

[135] A.I. Fengler, R.R. Marquardt, Water-soluble pentosans from rye: II. Effects on rate of dialysis and on the retention of nutrients by the chick, Cereal Chem. 65(4) (1988) 298-302. [136] P. Wang, H. Tao, Z. Jin, X. Xu, Impact of water extractable arabinoxylan from rye bran on the frozen steamed bread dough quality, Food Chem. 200 (2016) 117-124.

[137] Z. Merali, K. Marjamaa, A. Käsper, K. Kruus, A.P. Gunning, V.J. Morris, K.W. Waldron, Chemical characterization of hydrothermally pretreated and enzyme-digested wheat straw: An evaluation of recalcitrance, Food Chem. 198 (2016) 132-140. 
[138] T. Sasaki, T. Yasui, J. Matsuki, Influence of non-starch polysaccharides isolated from wheat flour on the gelatinization and gelation of wheat starches, Food Hydrocolloids 14(4) (2000) 295-303.

[139] H. Gruppen, R. Hamer, A. Voragen, Water-unextractable cell wall material from wheat flour. 2. Fractionation of alkali-extracted polymers and comparison with water-extractable arabinoxylans, Journal of Cereal Science 16(1) (1992) 53-67.

[140] B.A. Acosta-Estrada, J.A. Gutiérrez-Uribe, S.O. Serna-Saldívar, Bound phenolics in foods, a review, Food Chem. 152 (2014) 46-55.

[141] J. Michniewicz, C. Biliaderis, W. Bushuk, Water-insoluble pentosans of wheat: composition and some physical properties, Cereal Chem. 67(5) (1990) 434-439.

[142] E.H. Jung, S. Ran Kim, I.K. Hwang, T. Youl Ha, Hypoglycemic effects of a phenolic acid fraction of rice bran and ferulic acid in C57BL/KsJ-db/db mice, J. Agric. Food Chem. 55(24) (2007) 9800-9804.

[143] J. Snelders, E. Dornez, J.A. Delcour, C.M. Courtin, Ferulic acid content and appearance determine the antioxidant capacity of arabinoxylanoligosaccharides, J. Agric. Food Chem. 61(42) (2013) 10173-10182.

[144] C. Courtin, J. Delcour, Relative activity of endoxylanases towards water-extractable and water-unextractable arabinoxylan, Journal of Cereal Science 33(3) (2001) 301-312. [145] L. Jacquemin, R. Zeitoun, C. Sablayrolles, P.-Y. Pontalier, L. Rigal, Evaluation of the technical and environmental performances of extraction and purification processes of arabinoxylans from wheat straw and bran, Process Biochemistry 47(3) (2012) 373-380.

[146] C.B. Faulds, G. Mandalari, R.B. Lo Curto, G. Bisignano, K.W. Waldron, Influence of the arabinoxylan composition on the susceptibility of mono-and dimeric ferulic acid release by Humicola insolens feruloyl esterases, J. Sci. Food Agric. 86(11) (2006) 1623-1630.

[147] H. Gruppen, R. Hamer, A. Voragen, Barium hydroxide as a tool to extract pure arabinoxylans from water-insoluble cell wall material of wheat flour, Journal of Cereal Science 13(3) (1991) 275-290.

[148] C. Maes, J. Delcour, Alkaline hydrogen peroxide extraction of wheat bran non-starch polysaccharides, Journal of Cereal Science 34(1) (2001) 29-35.

[149] G. Mandalari, C.B. Faulds, A.I. Sancho, A. Saija, G. Bisignano, R. LoCurto, K.W. Waldron, Fractionation and characterisation of arabinoxylans from brewers' spent grain and wheat bran, Journal of Cereal Science 42(2) (2005) 205-212.

[150] S. Hashimoto, M. Shogren, L. Bolte, Y. Pomeranz, Cereal pentosans: their estimation and significance. 3. Pentosans in abraded grains and milling by-products, Cereal Chem. 64(1) (1987) 39-41.

[151] M.S. Dodevska, B.I. Djordjevic, S.S. Sobajic, I.D. Miletic, P.B. Djordjevic, V.S. Dimitrijevic-Sreckovic, Characterisation of dietary fibre components in cereals and legumes used in Serbian diet, Food Chem. 141(3) (2013) 1624-1629.

[152] M.Y. Kim, S.H. Lee, G.Y. Jang, H.J. Park, M. Li, S. Kim, Y.R. Lee, Y.H. Noh, J. Lee, H.S. Jeong, Effects of high hydrostatic pressure treatment on the enhancement of functional components of germinated rough rice (Oryza sativa L.), Food Chem. 166 (2015) 86-92.

[153] J. Hollmann, M. Lindhauer, Pilot-scale isolation of glucuronoarabinoxylans from wheat bran, Carbohydrate Polymers 59(2) (2005) 225-230.

[154] D. Koegelenberg, A.F. Chimphango, Effects of wheat-bran arabinoxylan as partial flour replacer on bread properties, Food Chem. 221 (2017) 1606-1613.

[155] J. Wang, E. Smits, R.M. Boom, M.A. Schutyser, Arabinoxylans concentrates from wheat bran by electrostatic separation, Journal of Food Engineering 155 (2015) 29-36. 
[156] I. Marcotuli, Y.S.-Y. Hsieh, J. Lahnstein, K. Yap, R.A. Burton, A. Blanco, G.B. Fincher, A. Gadaleta, Structural Variation and Content of Arabinoxylans in Endosperm and Bran of Durum Wheat (Triticum turgidum L.), J. Agric. Food Chem. 64(14) (2016) 2883-2892. [157] A. Pavlovich-Abril, O. Rouzaud-Sández, E. Carvajal-Millán, R.E. Navarro, R.M. RoblesSánchez, J.M. Barrón-Hoyos, Molecular characterization of water extractable arabinoxylans isolated from wheat fine bran and their effect on dough viscosity, LWT-Food Science and Technology 74 (2016) 484-492.

[158] H.B. Hansen, C.V. Rasmussen, K.E. Bach Knudsen, Å. Hansen, Effects of genotype and harvest year on content and composition of dietary fibre in rye (Secale cereale L) grain, J. Sci. Food Agric. 83(1) (2003) 76-85.

[159] Z. Sárossy, M. Tenkanen, L. Pitkänen, A.-B. Bjerre, D. Plackett, Extraction and chemical characterization of rye arabinoxylan and the effect of $\beta$-glucan on the mechanical and barrier properties of cast arabinoxylan films, Food hydrocolloids 30(1) (2013) 206-216. [160] Z. Zhang, C. Smith, W. Li, J. Ashworth, Characterization of nitric oxide modulatory activities of alkaline-extracted and enzymatic-modified arabinoxylans from corn bran in cultured human monocytes, J. Agric. Food Chem. 64(43) (2016) 8128-8137.

[161] J. Beaugrand, G. Chambat, V.W. Wong, F. Goubet, C. Rémond, G. Paës, S.

Benamrouche, P. Debeire, M. O'Donohue, B. Chabbert, Impact and efficiency of GH10 and GH11 thermostable endoxylanases on wheat bran and alkali-extractable arabinoxylans, Carbohydr. Res. 339(15) (2004) 2529-2540.

[162] M. Izydorczyk, J. Dexter, Barley $\beta$-glucans and arabinoxylans: Molecular structure, physicochemical properties, and uses in food products-a Review, Food Research International 41(9) (2008) 850-868.

[163] N.K. Ganguli, M.A. Turner, A simplified method for extracting water-extractable arabinoxylans from wheat flour, J. Sci. Food Agric. 88(11) (2008) 1905-1910.

[164] M. Fleury, M. Edney, L. Campbell, G. Crow, Total, water-soluble and acid-soluble arabinoxylans in western Canadian barleys, Canadian journal of plant science 77(2) (1997) 191-196.

[165] Z. Zhang, C. Smith, W. Li, Extraction and modification technology of arabinoxylans from cereal by-products: A critical review, Food research international 65 (2014) 423-436. [166] W. Shu-Lai Mok, M. Antal, Uncatalyzed solvolysis of whole biomass hemicellulose by hot compressed liquid water, Ind. Eng. Chem. Res. 31(4) (1992) 1157-1161.

[167] G. Garrote, H. Dominguez, J. Parajo, Hydrothermal processing of lignocellulosic materials, European Journal of Wood and Wood Products 57(3) (1999) 191-202. [168] T. Josefsson, H. Lennholm, G. Gellerstedt, Steam explosion of aspen wood. Characterisation of reaction products, Holzforschung 56(3) (2002) 289-297.

[169] A.A. Peterson, F. Vogel, R.P. Lachance, M. Fröling, M.J. Antal Jr, J.W. Tester, Thermochemical biofuel production in hydrothermal media: a review of sub-and supercritical water technologies, Energy Environ. Sci. 1(1) (2008) 32-65.

[170] M. Bergmans, G. Beldman, H. Gruppen, A. Voragen, Optimisation of the selective extraction of (glucurono) arabinoxylans from wheat bran: use of barium and calcium hydroxide solution at elevated temperatures, Journal of Cereal Science 23(3) (1996) 235245.

[171] F.C. de Figueiredo, A.F.A. Carvalho, M. Brienzo, T.S. Campioni, P. de Oliva-Neto, Chemical input reduction in the arabinoxylan and lignocellulose alkaline extraction and xylooligosaccharides production, Bioresource Technology (2016). 
[172] X. Zheng, L. Li, X. Wang, Molecular characterization of arabinoxylans from hull-less barley milling fractions, Molecules 16(4) (2011) 2743-2753.

[173] M. Aguedo, H.A. Ruiz, A. Richel, Non-alkaline solubilization of arabinoxylans from destarched wheat bran using hydrothermal microwave processing and comparison with the hydrolysis by an endoxylanase, Chemical Engineering and Processing: Process Intensification 96 (2015) 72-82.

[174] M. Aguedo, C. Fougnies, M. Dermience, A. Richel, Extraction by three processes of arabinoxylans from wheat bran and characterization of the fractions obtained, Carbohydrate polymers 105 (2014) 317-324.

[175] L.N. Malunga, T. Beta, Antioxidant capacity of water-extractable arabinoxylan from commercial barley, wheat, and wheat fractions, Cereal Chem. 92(1) (2015) 29-36.

[176] X. Sun, F. Xu, R. Sun, Z. Geng, P. Fowler, M. Baird, Characteristics of degraded hemicellulosic polymers obtained from steam exploded wheat straw, Carbohydrate Polymers 60(1) (2005) 15-26.

[177] P. Etanol, FRACTIONATION OF HEMICELLULOSE FROM RICE STRAW BY ALKALINE EXTRACTION AND ETHANOL PRECIPITATION, Malaysian Journal of Analytical Sciences 20(2) (2016) 329-334.

[178] E. Escarnot, M. Aguedo, M. Paquot, Enzymatic hydrolysis of arabinoxylans from spelt bran and hull, Journal of Cereal Science 55(2) (2012) 243-253.

[179] N.M. Anson, R. van den Berg, R. Havenaar, A. Bast, G.R. Haenen, Bioavailability of ferulic acid is determined by its bioaccessibility, Journal of Cereal Science 49(2) (2009) 296300.

[180] B. Zhang, G. Ramesh, S. Uematsu, S. Akira, W.B. Reeves, TLR4 signaling mediates inflammation and tissue injury in nephrotoxicity, J. Am. Soc. Nephrol. 19(5) (2008) 923-932. [181] P. Falck, A. Aronsson, C. Grey, H. Stålbrand, E.N. Karlsson, P. Adlercreutz, Production of arabinoxylan-oligosaccharide mixtures of varying composition from rye bran by a combination of process conditions and type of xylanase, Bioresource technology 174 (2014) 118-125.

[182] C. Cara, E. Ruiz, I. Ballesteros, M.J. Negro, E. Castro, Enhanced enzymatic hydrolysis of olive tree wood by steam explosion and alkaline peroxide delignification, Process Biochemistry 41(2) (2006) 423-429.

[183] D.J. Rose, G.E. Inglett, Production of feruloylated arabinoxylo-oligosaccharides from maize (Zea mays) bran by microwave-assisted autohydrolysis, Food Chem. 119(4) (2010) 1613-1618.

[184] R. Zeitoun, P.Y. Pontalier, P. Marechal, L. Rigal, Twin-screw extrusion for hemicellulose recovery: Influence on extract purity and purification performance, Bioresource technology 101(23) (2010) 9348-9354.

[185] A.A. Roos, T. Persson, H. Krawczyk, G. Zacchi, H. Stålbrand, Extraction of water-soluble hemicelluloses from barley husks, Bioresource technology 100(2) (2009) 763-769.

[186] E. Coelho, M.A.M. Rocha, J.A. Saraiva, M.A. Coimbra, Microwave superheated water and dilute alkali extraction of brewers' spent grain arabinoxylans and arabinoxylooligosaccharides, Carbohydrate polymers 99 (2014) 415-422.

[187] T. Yoshida, S. Tsubaki, Y. Teramoto, J.-i. Azuma, Optimization of microwave-assisted extraction of carbohydrates from industrial waste of corn starch production using response surface methodology, Bioresource technology 101(20) (2010) 7820-7826. 
[188] M.A. Brennan, E. Derbyshire, B.K. Tiwari, C.S. Brennan, Ready-to-eat snack products: the role of extrusion technology in developing consumer acceptable and nutritious snacks, Int. J. Food Sci. Technol. 48(5) (2013) 893-902.

[189] M.T. Masatcioglu, E. Yalcin, P.J. Hwan, G.-H. Ryu, S. Celik, H. Koksel, Hull-less barley flour supplemented corn extrudates produced by conventional extrusion and $\mathrm{CO} 2$ injection process, Innov. Food Sci. Emerg. Technol. 26 (2014) 302-309.

[190] H. Rohm, C. Brennan, C. Turner, E. Günther, G. Campbell, I. Hernando, S. Struck, V. Kontogiorgos, Adding value to fruit processing waste: innovative ways to incorporate fibers from berry pomace in baked and extruded cereal-based foods-a SUSFOOD project, Foods 4(4) (2015) 690-697.

[191] R.P. Rathod, U.S. Annapure, Effect of extrusion process on antinutritional factors and protein and starch digestibility of lentil splits, LWT-Food Science and Technology 66 (2016) 114-123.

[192] M.-C. Ralet, M.A. Axelos, J.-F. Thibault, Gelation properties of extruded lemon cell walls and their water-soluble pectins, Carbohydr. Res. 260(2) (1994) 271-282.

[193] M.-C. Ralet, G. Della Valle, J.-F. Thibault, Raw and extruded fibre from pea hulls. Part I: Composition and physico-chemical properties, Carbohydrate Polymers 20(1) (1993) 17-23. [194] M.-C. Ralet, J.-F. Thibault, G. Della Valle, Influence of extrusion-cooking on the physico-chemical properties of wheat bran, Journal of Cereal Science 11(3) (1990) 249-259. [195] S. Singkhornart, S.G. Lee, G.H. Ryu, Influence of twin-screw extrusion on soluble arabinoxylans and corn fiber gum from corn fiber, J. Sci. Food Agric. 93(12) (2013) 30463054.

[196] W. Wang, C. Klopfenstein, J. Ponte Jr, Baking Quality of the Wheat Bran, Cereal Chem. 70(6) (1993) 707-711.

[197] M.E. Camire, Z. JIANXIN, D.A. Violette, In vitro binding of bile acids by extruted potato peels, J. Agric. Food Chem. 41(12) (1993) 2391-2394.

[198] M. Ralet, J. Thibault, G. Della Valle, Solubilization of sugar-beet pulp cell wall polysaccharides by extrusion-cooking, Lebensmittel Wissenschaft und Technologie 24 (1991) 107-112.

[199] E. Margareta, G.-L. Nyman, Importance of processing for physico-chemical and physiological properties of dietary fibre, Proc. Nutr. Soc. 62(01) (2003) 187-192.

[200] S. Hughes, P. Shewry, L. Li, G. Gibson, M. Sanz, R. Rastall, In vitro fermentation by human fecal microflora of wheat arabinoxylans, J. Agric. Food Chem. 55(11) (2007) 45894595.

[201] D. Gualberto, C. Bergman, M. Kazemzadeh, C. Weber, Effect of extrusion processing on the soluble and insoluble fiber, and phytic acid contents of cereal brans, Plant Foods Hum. Nutr. 51(3) (1997) 187-198.

[202] D. Long, F. Ye, G. Zhao, Optimization and characterization of wheat bran modified by in situ enhanced CO 2 blasting extrusion, LWT-Food Science and Technology 59(2) (2014) 605-611. 


\section{Figure legends:}

Figure 1. Arabinoxylans (AXs) structure.

Figure 2. Simplified schematic representation of (a) wheat flour and (b) wheat bran AXs. Substituents above and below the backbone represent $\mathrm{C}(\mathrm{O})-2$ and $\mathrm{C}(\mathrm{O})-3$ positions, respectively. 


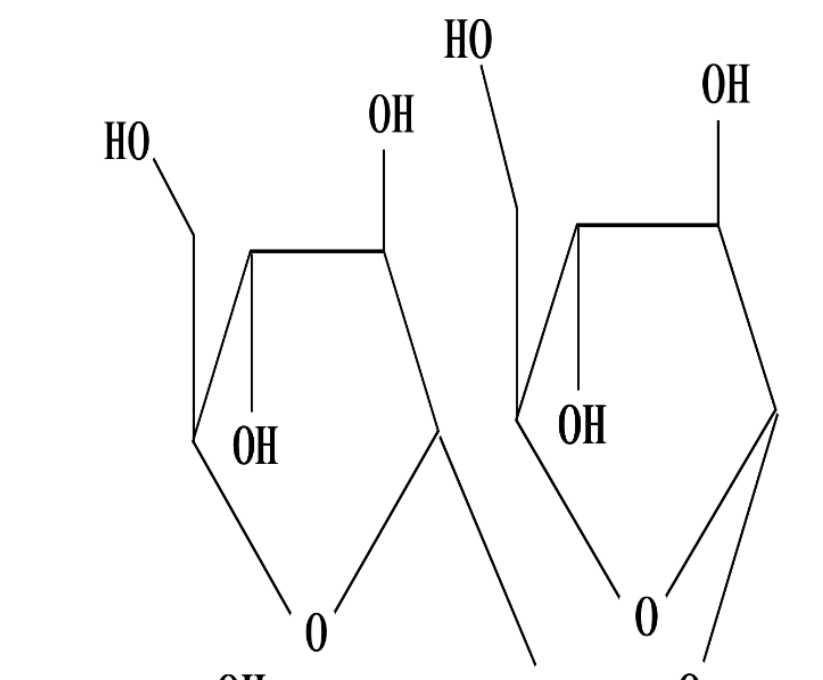

\section{Xylose Backbone}

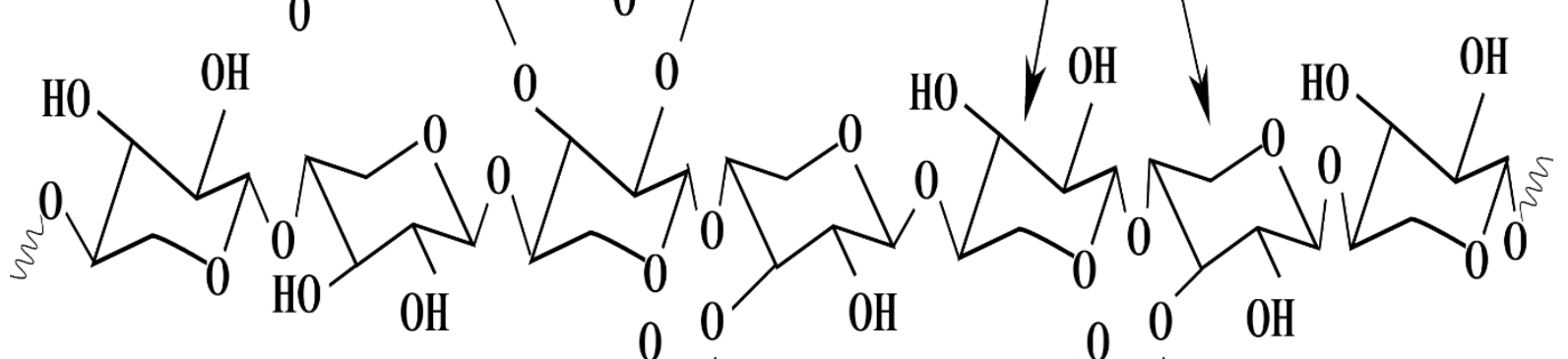

Ferulic Acid
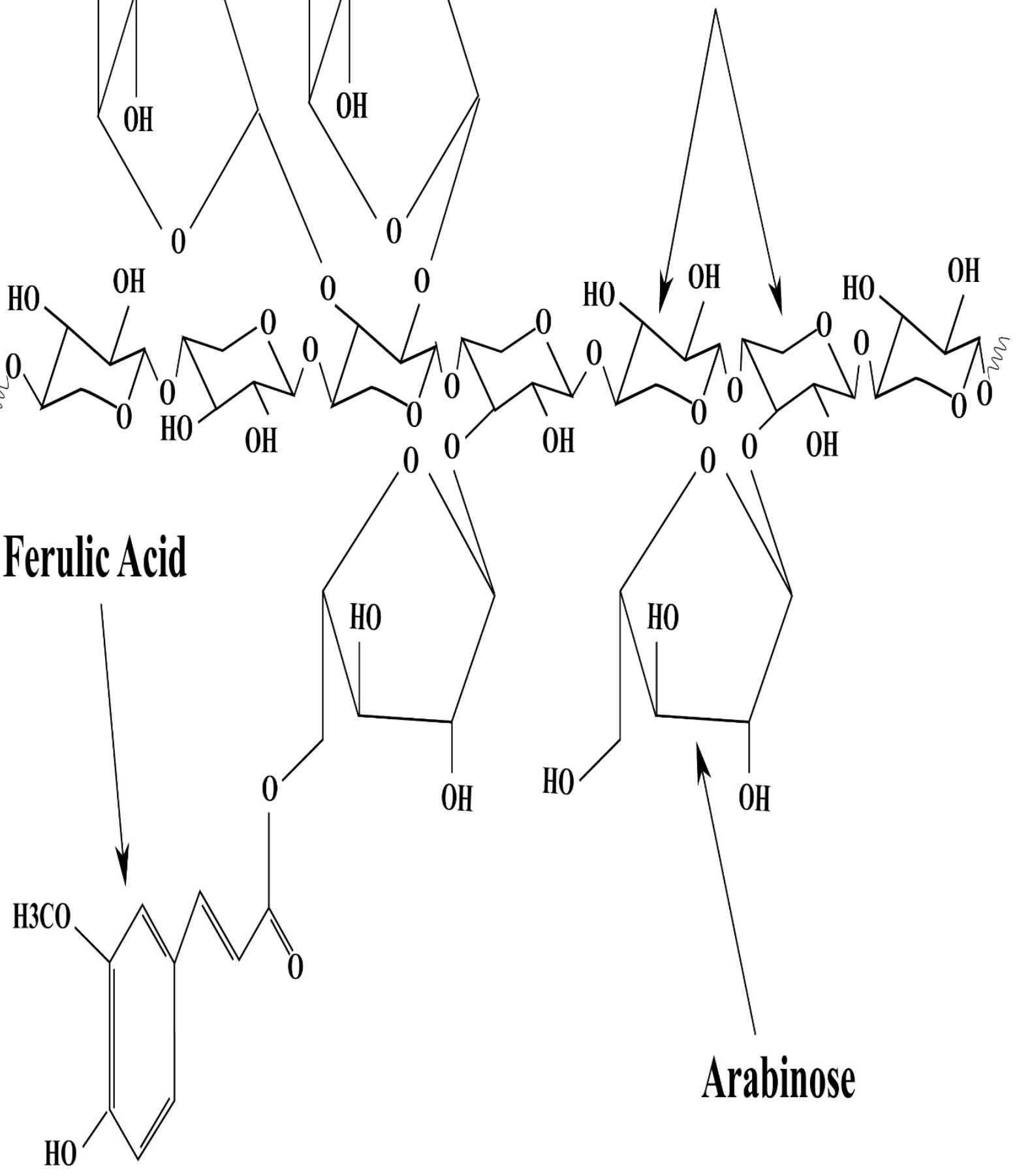
a

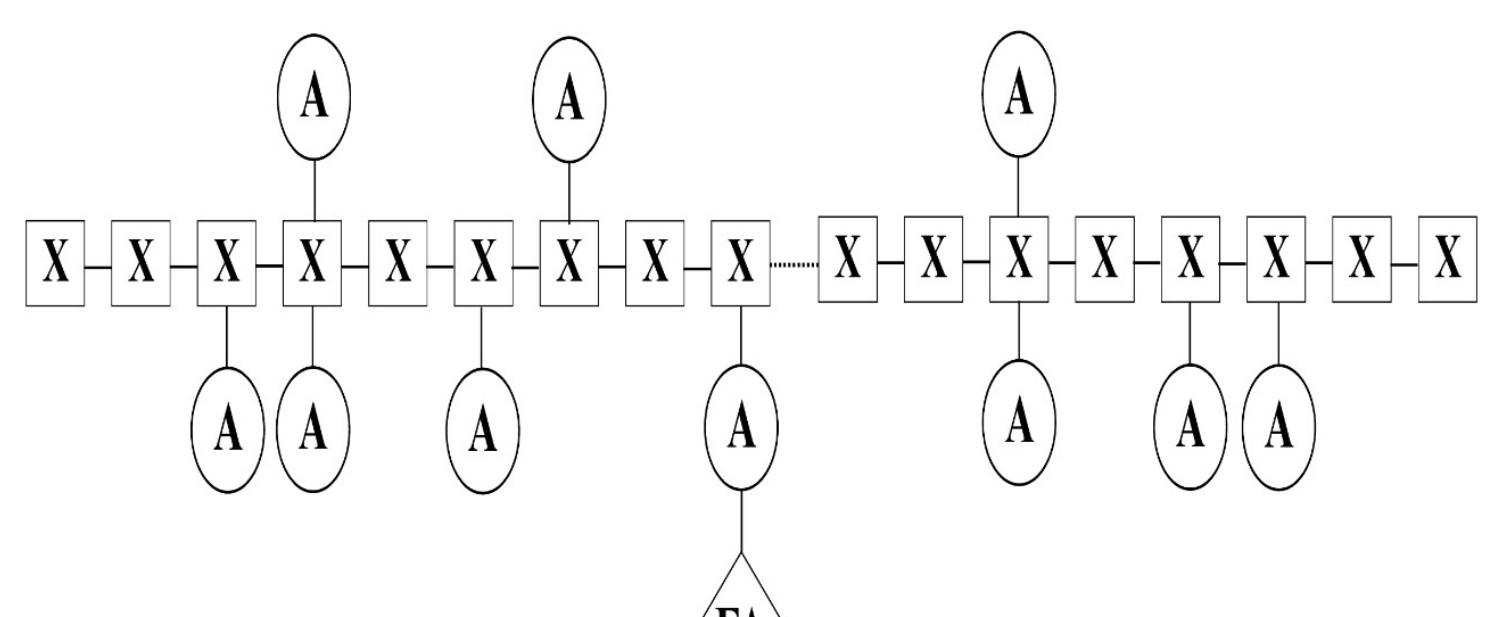

FA

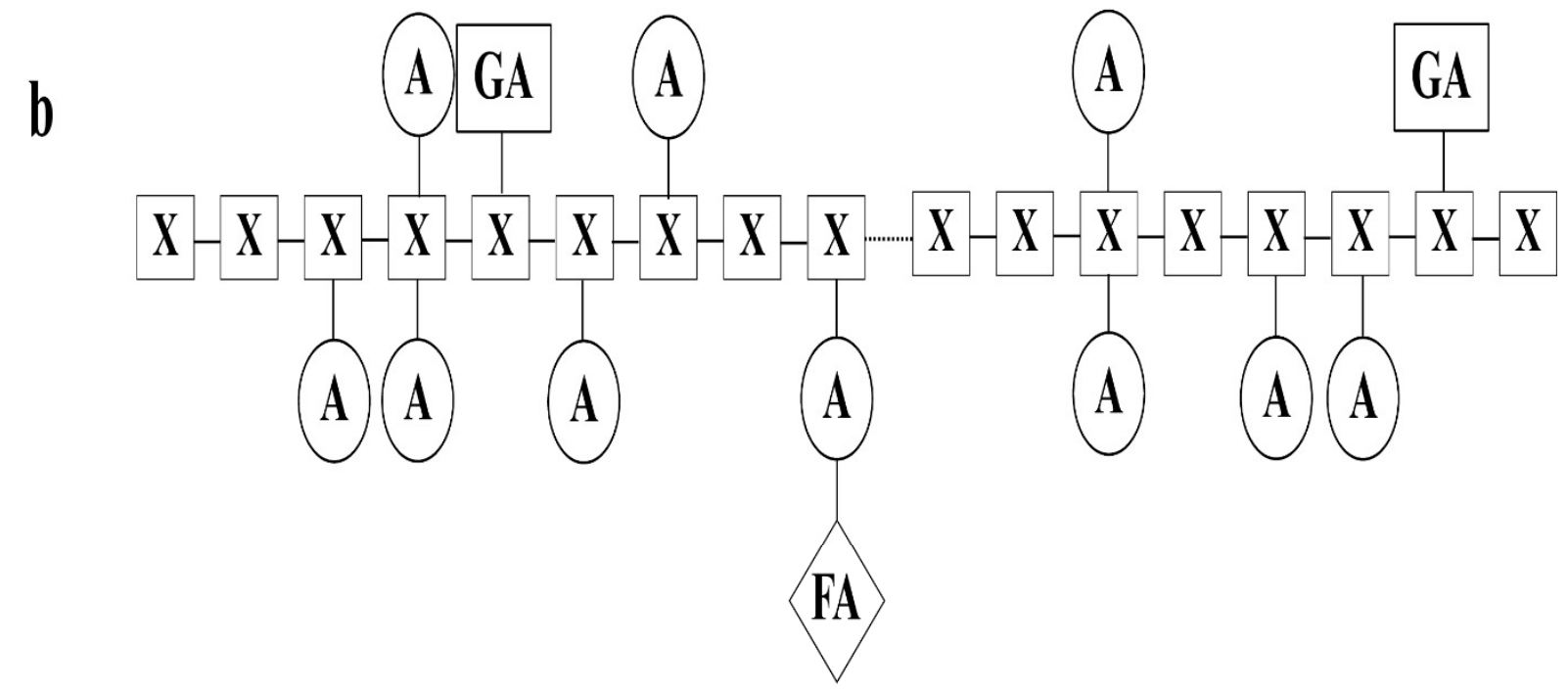

FA Ferulic Acid A Arabinofuranose

GA Glucuronic Acid X Xylopyranose 


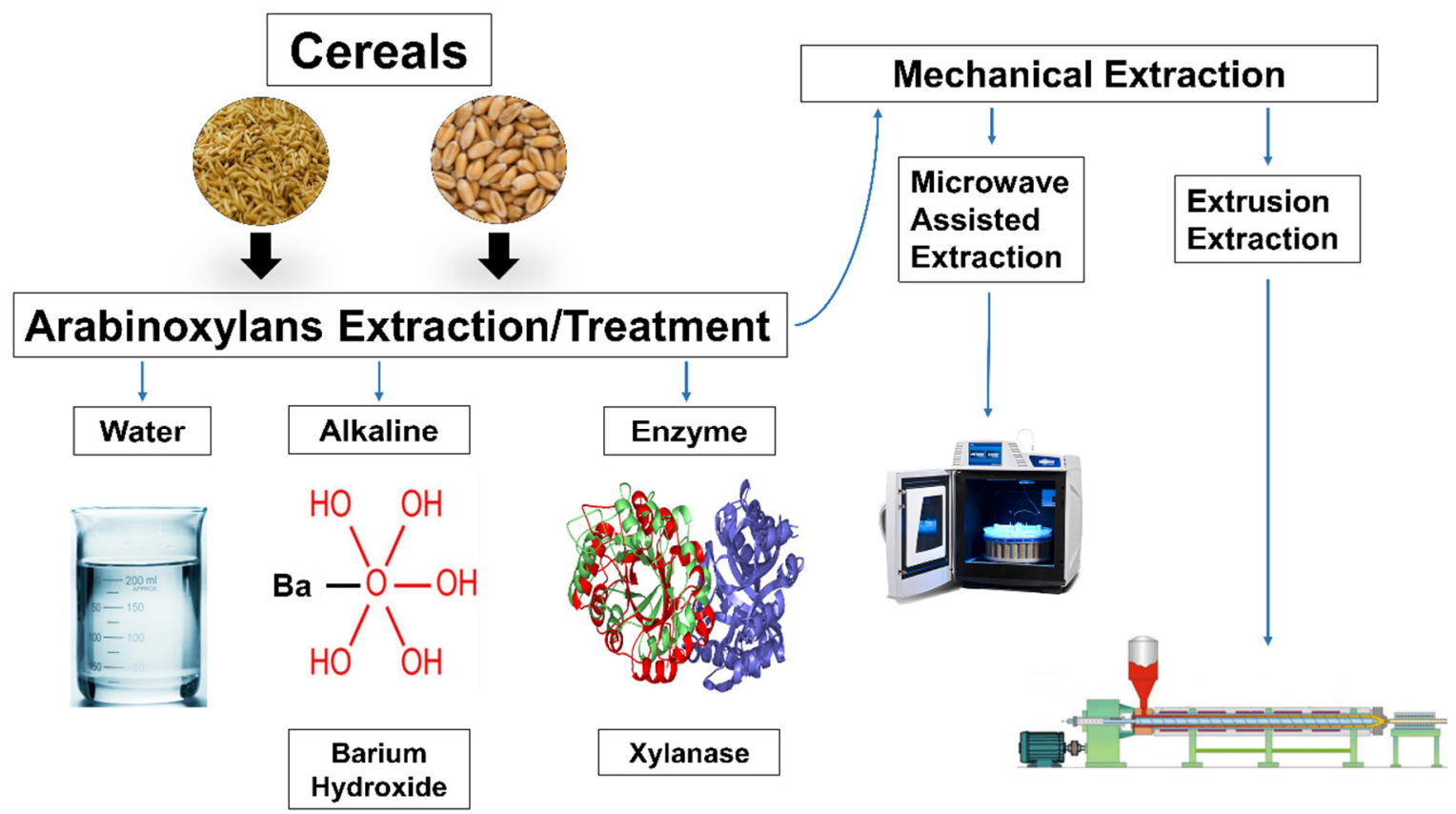

